\title{
Diferenças de comportamento inovador entre empresas nacionais e estrangeiras no Brasil
}

\author{
Ana Urraca Ruiz \\ Universidade Federal Fluminense (UFF) \\ Renata Bhawan \\ Universidade Federal Fluminense (UFF)
}

Recebido: 08/09/2008 Versão revisada (entregue): 28/04/2009 Aprovado: 04/05/2009

\section{RESUMO}

Este artigo tem como objetivo comparar o comportamento inovador de empresas multinacionais (EMN) e nacionais (ENA) no Brasil por setor de atividade industrial. As variáveis de comparação são as que a literatura tradicionalmente recomenda (intensidade de mudança tecnológica, insumos, produtos, aprendizado e trajetória tecnológica) e que se encontram na Pintec 2003 do IBGE. A comparação é realizada mediante o cálculo de índices de semelhança e coeficientes de correlação entre as propensôes a realizar as atividades definidas entre ambos os grupos de empresas e por setor, assim como por meio de indicadores de autonomia e dependência tecnológica. Os principais resultados mostram que: i) as EMN são mais propensas a inovar, mas não são altamente inovadoras; ii) as diferenças de comportamento entre ambos os grupos estudados são muito reduzidas em termos agregados, na maior parte dos setores e para todas as variáveis examinadas, o que significa que a atividade inovadora de cada empresa é fortemente determinada por imperativos tecnológicos setoriais; iii) os setores que apresentam maiores diferenças de comportamento são praticamente os mesmos para a maior parte das variáveis objeto de comparação (confecção, metalurgia, indústrias diversas,

\footnotetext{
As autoras agradecem ao IBGE, a João Alberto De Negri e a Fernando Freitas pela ajuda inestimável no tratamento das informações da Pintec 2003, as quais foram disponibilizadas na forma específica em que foram solicitadas, sem o que este trabalho não teria sido possível. As autoras agradecem também aos comentários e às sugestões realizados por três avaliadores anônimos indicados pela RBI.
} 
Ana Urraca Ruiz, Renata Bhawan

refino de petróleo, veículos e instrumentos e equipamentos de comunicaçôes), o que revela que os aspectos relativos à estrutura e organização da firma podem ser mais relevantes que os imperativos tecnológicos setoriais.

PALAVRAS-Chave $\mid$ inovação; capital estrangeiro; Brasil; indústria; empresas multinacionais.

CÓdIGOS JEL $\mid$ O31

\section{Differences of innovative behavior among local and foreign companies in Brazil}

\section{ABSTRACT}

This article aims to compare innovative behavior between multinational (EMN) and national (ENA) firms in Brazil by sector of industrial activity. The variables of comparison are those traditionally recommended by literature (intensity of technological change, sources and results of innovation, learning and technological trajectory) and which are in Pintec 2003 from IBGE. The comparison is performed through the calculation of similarity indexes and correlation coefficients between the propensity to execute the different innovative activities between both groups (ENA and EMN) and by sectors, as well as indexes of technological autonomy and dependency. The main results show that: i) EMN have more propensity to be innovative, but not to be "highly innovative"; ii) for all variables examined and for most sectors, the differences in innovative behavior between the two groups are irrelevant in aggregate terms, which means that the innovative activity of the firm is more driven by sectorial technological imperatives; and iii) for most of the variables object of comparison, the sectors that have major differences in behavior are practically the same (manufacture of wearing apparel, metallurgy, other industrial products, refined petroleum products, motor vehicles, instruments and communications equipment), which suggest that the aspects related to structure and organization of the firm may be more relevant than the sectorial technological imperatives.

KEYWORDS I innovation; foreign capital; Brazil; industry; multinational corporations.

JEL-CODES $\mid$ O31 


\section{Introdução}

Uma abordagem tradicional para analisar o ritmo e direção da mudança tecnológica setorial é a que estabelece padrões de comportamento inovador entre firmas que, incluindo aquelas pertencentes a diferentes setores, compartilham características similares nos seus processos de inovação. Estas semelhanças são dadas por imperativos tecnológicos, produtivos, organizativos, cognitivos e mercadológicos geralmente relacionados a cada setor e associados aos processos de produção e de busca, os quais definirão tarefas específicas de inovação que são comuns ao conjunto de firmas que operam na mesma indústria e àquelas que, sendo de diferentes setores, compartilham tais tarefas. Dessa forma, uma empresa do setor madeireiro deveria ser mais próxima (similar em seus processos de inovação) de uma empresa têxtil do que de uma química, uma vez que tais imperativos determinam a natureza dessas semelhanças (importância das inovações de processo desenvolvidas fora do setor para a redução de custos como estratégia competitiva; dificuldade de diferenciação de produtos; importância da marca como mecanismo de apropriabilidade; intensidade na utilização de fator trabalho, etc.).

Inicialmente essa abordagem permitiu caracterizar os processos de inovação das firmas por meio de um conjunto de variáveis consonantes com os pressupostos teóricos dos regimes tecnológicos setoriais. Concretamente, as variáveis seriam: os insumos do processo e sua localização interna ou externa (fontes de inovação); os resultados do processo; os determinantes e o foco da trajetória tecnológica; o grau de diversificação tecnológica e alguma variável relativa à estrutura de mercado (PAVITT, 1984).

Além dos fatores setoriais, a literatura aponta para as características da firma (tamanho, estrutura organizacional, etc.) como importantes determinantes de aspectos dos processos de inovação, como a origem de recursos ou o aprendizado. As especificidades corporativas geram também diferentes comportamentos, ou seja, formas distintas de empreender a atividade inovadora, mesmo em empresas que operam dentro do mesmo setor, conforme as assimetrias no sentido de Dosi (1988). Nestes casos, as especificidades da firma são mais importantes do que os imperativos setoriais na determinação da sua atividade inovadora. Se existem semelhanças de comportamento inovador entre firmas que operam dentro do mesmo setor, os imperativos setoriais são altamente determinantes, dado que afetam a todas elas por igual.

Uma questão fundamental, mas pouco explorada pela literatura, relaciona-se aos aspectos organizacionais vinculados ao controle da firma por capital estrangeiro 
como determinantes da sua atividade inovadora. Este aspecto é especialmente relevante em países que não são líderes, mas seguidores, como no caso do Brasil, por duas razôes: pela vinculação que existe entre liderança tecnológica e internacionalização produtiva; porque as empresas multinacionais podem ser líderes tecnológicas nos países hospedeiros, dada a brecha tecnológica entre estes e os países de origem. As particularidades dos processos de inovação que ultrapassam as fronteiras nacionais (transnacionais) podem levar as empresas que operam no mesmo setor, nos mesmos mercados e se sujeitam a imperativos tecnológicos similares a apresentarem diferenças nas características dos seus processos de inovação.

Nesse sentido, a partir dos dados da Pintec 2003, o artigo se propõe a:

estudar as diferenças de comportamento inovador entre empresas brasileiras (ENA) e empresas do mesmo setor de atividade que têm participação de capital estrangeiro e se localizam no Brasil (EMN);

apontar o balanço da natureza dos determinantes do processo inovador, isto é, estabelecer a importância relativa dos fatores decorrentes de estruturas organizativas específicas da firma em contraste àqueles que resultam dos imperativos setoriais onde ela atua.

O trabalho considera as empresas com participação de capital estrangeiro como sendo subsidiárias (ou afiliadas) de suas matrizes e são tomadas como unidades "independentes" (externas à matriz) no que se refere às atividades tecnológicas que desempenham, mas que sem dúvida interagem com o resto da corporação.

Além desta introdução, o artigo possui três partes. A primeira contém uma breve exposição teórica sobre por que seriam previsíveis comportamentos diferentes entre EMNs e ENAs. A segunda consiste em uma comparação entre os grupos de firmas utilizando índices de semelhança e coeficientes de correlação. A terceira parte apresenta os principais resultados da análise.

\section{Comportamento inovador transnacional}

A pesquisa e desenvolvimento $(\mathrm{P} \& \mathrm{D})$ transnacional está vinculada ao tipo de atividade tecnológica que as EMNs pretendem desenvolver e aos objetivos associados a estas atividades, ou seja, o tipo de competência (área técnica) que está sendo internacionalizada e o propósito de tal internacionalização (exploração local-global de um novo produto ou processo, busca de ativos complementares, desenvolvimento de uma competência ou capacidade não adquirida in-house, adaptação de competências-vantagens domésticas aos mercados de destino, etc.) (PEARCE, 1992; 
DUNNING, 1994; CANTWELL, 1995). Além desses fatores, a P\&D transnacional vem também determinada por aspectos institucionais característicos do país de destino, como a proteção intelectual ou a dotação de engenheiros e pesquisadores, assim como por outros aspectos relacionados com a firma subsidiária, como sua propensão a exportar, o nível de conhecimento acumulado ou a interação entre processos de busca realizados entre os distintos níveis de P\&D (laboratórios ou planta) (ITO; WAKASUGI, 2007).

A descentralização geográfica da $\mathrm{P} \& \mathrm{D}$ das EMNs pode ser explicada a partir de seu padrão de diversificação e especialização, já que a complexidade e interdependência entre tecnologias podem levar a tentar o acesso a novas linhas de pesquisa além das fronteiras nacionais (CANTWELL; JANNE, 1999), monitorando desenvolvimentos que têm lugar em diferentes partes do mundo, o que é mais relevante quanto mais complexas são as tecnologias e mais elevados são os custos de $\mathrm{P} \& \mathrm{D}$ (PATEL; VEGA, 1999). Se a descentralização geográfica está associada à simples exploração da vantagem tecnológica do país hospedeiro, a $\mathrm{P} \& \mathrm{D}$ transnacional pode estar orientada a aliviar debilidades tecnológicas internas, podendo haver duplicidade de esforços e de competências entre os domésticos e os transnacionais.

O trabalho de Cantwell e Janne (1999) revela que existem diferentes hierarquias entre centros de P\&D em cada indústria. Quando se trata de centros de excelência de EMNs líderes, a busca por tecnologias interdependentes acaba gerando padrōes de diversificação tecnológica por área geográfica diferentes dos padrōes de seus países de origem. Sua capacidade de absorção é maior e, consequentemente, a capacidade de diversificar tecnologicamente também. Em contrapartida, as subsidiárias de EMNs que constituem centros de pesquisa de menor ordem são menos ambiciosas no desenvolvimento de sua atividade tecnológica exterior. Estas têm percepção mais reduzida do conhecimento que é novo e relevante e sua capacidade para abrir novas linhas de negócios mostra-se mais restrita. Têm como objetivo tomar as vantagens da experiência tecnológica local para adaptar os produtos e processos desenvolvidos em seus países de origem aos mercados de destino e, assim, tendem a desenvolver um padrão de réplica da especialização tecnológica atingida em seus países de origem (duplicidade de esforços).

As EMNs, fora de seus países de origem, são mais ativas tecnologicamente em áreas técnicas intensivas em $P \& D$ onde podem formar alianças estratégicas (farmácia, computação, telecomunicações e materiais) e onde são fortes ou foram desenvolvidas vantagens tecnológicas domésticas (PATEL; VEGA, 1999). No entanto, o habitual é que as EMNs invistam em tecnologia no exterior para a adaptação e para o 
provimento de apoio técnico às outras plantas, sendo muito reduzidos os casos de monitoramento dos desenvolvimentos de centros de excelência locais, especialmente em países seguidores.

\subsection{As fontes de inovação}

As fontes de inovação estão relacionadas com o locus onde são geradas as inovações. A literatura distingue como fontes aquelas que representam insumos no processo de inovação e as que representam fontes de conhecimento (MANSFIELD; RAPOPORTS, 1975; VON HIPPEL, 1988). A origem do capital (nacional ou estrangeiro) de uma empresa inovadora atinge, principalmente, dois aspectos da alocação de recursos à inovação: a composição entre recursos próprios e aquisição de terceiros; a organização e localização da P\&D.

No que se refere ao primeiro aspecto, as EMNs caracterizam-se por maior balanço no uso de fontes internas e externas. Teoricamente, existe uma relação positiva entre utilização de recursos internos e externos, isto é, quanto maiores são as capacidades derivadas da $\mathrm{P} \& \mathrm{D}$ interna, maior a propensão a adquirir capacitações externas, o que significa que existe certa substitutibilidade entre ambas, dado que parte dos desenvolvimentos internos se substituem por desenvolvimentos externos (KUROKAWA, 1992). Partindo de outra perspectiva, a relação entre o uso de fontes internas e externas pode ser negativa, isto é, quanto maior a capacitação derivada dos desenvolvimentos internos, menor a propensão a adquirir capacitaçôes externas e vice-versa. Neste caso, diz-se que há complementaridade entre ambas as fontes, dado que, quando uma é escassa, o processo de inovação se complementa com a outra (COHEN; LEVINTHAL, 1989).

A evidência empírica apoia ambas as justificativas, embora a versão sobre relação positiva tenha maior consistência teórica, fundamentalmente em setores com elevadas oportunidades tecnológicas, onde o processo de inovação depende em grande medida dos fluxos de informação e onde a P\&D permite assimilar tecnologias adquiridas externamente.

As EMNs caracterizam-se pela substitutibilidade de fontes internas por externas (relação positiva) porque costumam atuar em setores onde as oportunidades tecnológicas são elevadas e porque uma grande parte do conhecimento básico sobre competências centrais procede da matriz, localizada no exterior. Isso ocorre especialmente quando os esforços em pesquisa são de adaptação a mercados locais, o que é mais frequente em países seguidores. Em qualquer caso, apesar das vantagens de 
internalização, as subsidiárias não seguem comportamento independente da matriz e das demais subsidiárias na alocação de recursos para a inovação. Se ademais a EMN é líder tecnológica, o acesso ao conhecimento tecnológico gerado pela própria firma, mas em unidades externas, garante à EMN a liderança tecnológica nos lugares onde ela é ativa tecnológica e economicamente.

Sob um modelo organizacional hierárquico, no qual a matriz é responsável por desenvolver boa parte da P\&D e gerar recursos, a subsidiária acaba alocando recursos tecnológicos que adquire da casa matriz e permanece com pouca autonomia nesse campo, ou seja, a subsidiária torna-se cada vez mais propensa a utilizar recursos externos. Sob um modelo organizacional horizontal ou em rede, as subsidiárias também adquirem parte de seus recursos tecnológicos de outras unidades da rede e, embora sua autonomia tecnológica seja maior que no caso anterior, tais subsidiárias ainda se mostram mais dependentes do que as domésticas não vinculadas ao capital exterior. Assim, nos setores onde há alta participação de capital estrangeiro, espera-se maior utilização de fontes externas em relação às internas, especialmente a tecnologia importada, devido a essa especificidade do comportamento inovador das EMNs.

A organização e a localização da $P \& D$ transnacional também afetam a alocação de recursos à inovação pelas EMNs. Embora a P\&D transnacional tenha crescido rapidamente nas economias avançadas, as unidades de pesquisa têm apresentado certa rigidez locacional e baixa "taxa de mortalidade". A maior parte dos padrōes locacionais de $\mathrm{P} \& \mathrm{D}$ das indústrias mudou muito pouco desde seu estabelecimento. A baixa mobilidade das unidades de pesquisa pode ser explicada não só pelo fato de o desenvolvimento da pesquisa ser custo-intensivo em termos de localização, como também pela possibilidade de perda do suporte (infraestrutura) necessário ao desenvolvimento da P\&D caso haja mudança da unidade para outro lugar (Gibbs, Alderman, Oakey e Thwaits apud HOWELLS, 1990). Essa rigidez geográfica da localização da P\&D é ainda maior quando se considera que, com o objetivo de manter um bom fluxo de informações, as novas unidades são instaladas perto da ou na própria região onde a empresa já possui outras unidades de pesquisa.

A alocação de recursos à inovação transnacional está fortemente relacionada com o tipo e a natureza da atividade tecnológica empreendida (adaptativa ou de monitoramento) e com a intensidade do esforço tecnológico que será realizado. O tamanho e a intensidade do esforço aumentaram em virtude de quatro fatores (GERYBADZE; REGER, 1999):

- o crescimento da escala em pesquisa;

- o aumento da internacionalização dos recursos à inovação; 
- os fluxos de conhecimento entre organizações;

- a expansão das redes de comunicação.

A ampliação da escala em pesquisa é um fenômeno registrado tanto no plano nacional quanto no da firma. As empresas, que muitas vezes operavam em apenas um lugar, passaram a gerenciar pesquisas de unidades em localidades geograficamente espalhadas. As unidades de $\mathrm{P} \& \mathrm{D}$ tornaram-se cada vez mais especializadas em termos de atividades desenvolvidas, pessoal e equipamentos laboratoriais, o que poderia levar a dificuldades nos fluxos de informações entre unidades.

A crescente internacionalização da $\mathrm{P} \& \mathrm{D}$ sugere que no passado as unidades desse tipo localizadas além de suas fronteiras faziam, basicamente, modificações e desenvolvimentos sobre inovaçôes realizadas pela casa matriz para se adaptarem à demanda dos países hospedeiros. Com a diminuição da relevância dos mercados de origem, as EMNs passaram a estabelecer processos de P\&D mais integrados internacionalmente com unidades transnacionais cada vez mais especializadas, tanto em países em desenvolvimento quanto em outros países industrializados.

O aumento dos fluxos de conhecimento e comunicação entre as organizações, favorecido pela maior disponibilidade de informaçóes on-line e pelas redes de comunicação, e o aumento do custo de $\mathrm{P} \& \mathrm{D}$ revelaram a necessidade de maior compartilhamento do risco e maior articulação entre as EMNs e as locais, favorecendo a formação de joint ventures e outros tipos de acordos de colaboração.

Por essas razões, as EMNs podem ser caracterizadas como dinâmicas tecnologicamente fora de seus países de origem, levando suas subsidiárias a apresentar intensidades em P\&D semelhantes ou, inclusive, superiores às registradas por empresas locais. ${ }^{1}$ As atividades de P\&D praticadas por EMNs nos países hospedeiros mostram-se relevantes em relação às atividades desenvolvidas pelas empresas locais, inclusive nos países líderes onde o comportamento inovador das empresas locais é mais independente da presença estrangeira.

\subsection{Os resultados da inovação}

Os resultados do processo de inovação podem ser estudados de acordo com seu tipo e grau. O tipo de resultado distingue inovação de produtos, processos e sistemas (OCDE, 1992). O grau de novidade diferencia inovação radical e incremental (OCDE, 1992).

1 São os casos da Coréia e de Bélgica, onde as EMNs apresentam intensidade de P\&D muito superior na comparação com as empresas locais. 
O tipo de inovação articula-se às peculiaridades produtivas e técnicas, como as relaçôes com fornecedores e clientes, a elasticidade de preço da demanda que define o grau de diferenciação de produto, etc. Em princípio, o resultado do balanço entre inovação de produtos e processos não deveria ver-se alterado pela natureza do capital da empresa. Já o balanço entre inovaçôes incrementais e radicais pode ser influenciado se a firma controladora é líder tecnológica ou se a sua vantagem de propriedade é repassada a suas subsidiárias para que estas atuem como líderes nos mercados locais.

O modelo de organização da P\&D transnacional "centro-periferia"” considera que o fluxo de tecnologia é unidirecional, da matriz para sua filial, e que o papel desempenhado pelas filiais é basicamente adaptativo, com algumas poucas inovações adicionais para atender ao mercado local (GERYBADZE; REGER, 1999). Sob este modelo organizacional, as subsidiárias raramente seriam responsáveis pela realização de inovaçóes radicais, cabendo a elas somente aquelas incrementais ou de adaptação e o melhoramento de produtos e processos desenvolvidos pela matriz. Já sob um modelo organizacional mais descentralizado, o cenário pode ser diferente. Diante da duplicação de esforços, a especialização de algumas unidades para além de suas fronteiras em determinadas linhas de pesquisa pode, inclusive, possibilitar o surgimento de "centros de excelência" transnacionais. Estes, por sua vez, podem mesmo desenvolver inovaçôes radicais. Tais centros de excelência surgem tanto pelo desenvolvimento de produtos adaptados aos mercados locais ${ }^{3}$ como pela busca de ativos complementares e novas linhas de negócios nos países de destino. ${ }^{4}$

Finalmente, a descentralização da $\mathrm{P} \& \mathrm{D}$ envolve estratégias de patenteamento globais, dependendo de como a corporação determina a proteção de seus mercados nos diferentes pontos. Assim, mesmo não tendo participado diretamente da pesquisa,uma unidade pode ser titular de patentes que representam inovação no país onde está localizada, se isso permitir a proteção do mercado local ou nele criar liderança. Este constituiria um efeito perverso, dado que as subsidiárias apareceriam como muito ativas tecnologicamente quando, na realidade, podem ser ou não. ${ }^{5}$

2 No modelo centro-periferia, o país de origem concentra a quase totalidade das decisões estratégicas, articulando e coordenando as atividades desenvolvidas por suas subsidiárias em outros países. Mais especificamente, define as linhas de pesquisa, desenvolve P\&D básica e transfere o conhecimento gerado para suas subsidiárias.

3 Tal é o caso de desenvolvimento do motor Flexpower pela Bosch, no Brasil.

4 Por exemplo, os laboratórios da Bayer de pesquisa em biotecnologia próximos à Universidade de Stanford, nos Estados Unidos.

5 Uma evidência desse efeito reside na diferença entre o registro do depositante e o registro do inventor em patentes depositadas por empresas multinacionais. 
Pelas razões apontadas, parece plausível que EMNs apresentem comportamento inovador distinto em termos de resultados, mostrando maior nível de novidade das suas inovaçōes vis-à-vis as empresas locais.

\section{Diferenças de comportamento inovador entre empresas nacionais e multinacionais no Brasil}

\subsection{Base de dados e outros aspectos metodológicos}

A análise empírica utiliza tabulações especiais de microdados da Pintec 2003. Empregou-se um conceito diferente de empresa inovadora, sendo esta definida como firma que destina recursos à inovação, obtém resultados ou realiza inovação de sistemas (ver anexo metodológico). A partir desta definição, estabeleceram-se dois grupos: um grupo com 60.228 empresas de capital estritamente nacional (ENA) e o outro com 1.704 empresas que registram participação estrangeira no capital controlador da empresa (EMN). De acordo com os dados fornecidos pelo IBGE, algumas informaçôes relativas a setores com menos de três empresas foram eliminadas para manter o sigilo estatístico. Nestes casos, os valores foram considerados iguais a zero. Assim, as indústrias de celulose e outras pastas, coque e combustíveis nucleares e reciclagem foram eliminadas da análise por não apresentarem informaçôes suficientes de EMNs inovadoras para realização do estudo. No total, trabalhou-se com 28 setores da CNAE.

As diferenças de comportamento inovador entre EMNs e ENAs foram medidas por meio de indicadores de distância entre as propensōes registradas para ambos os grupos. Os indicadores de distância são índices de semelhança (IS), definidos como $I S_{i}=\sum_{i=1}^{n}\left|p_{i}^{E M N}-p_{i}^{E N A}\right|$ onde $p_{i}^{E M N}$ é a propensão registrada pela variável em análise no setor i-ésimo para empresas com participação de capital estrangeiro e $p_{i}^{E N A}$ corresponde à mesma propensão para as nacionais. Como as propensões setoriais variam entre 0 e 1, o IS também oscila entre esses valores. Se as propensões são as mesmas entre EMNs e ENAs, a distância é igual a 0 e não há diferença de comportamento entre os grupos.

As distâncias agregadas para cada variável correspondem à soma dos ISi para todos os setores. Dado que o valor máximo do ISi é 1 , o valor máximo das distâncias agregadas para os 28 setores é de 28 .

As propensões são indicadores de probabilidade, pois representam o número de casos (empresas) que se incluem na variável sobre o número total de casos (número 
de empresas inovadoras em cada subgrupo). ${ }^{6}$ Dado que os conjuntos de empresas são disjuntos, o índice de semelhança não apresenta distorções pela maior ou menor presença de EMNs em cada setor. No entanto, este indicador tem duas limitações. Dado que ele mede distâncias absolutas, tende a ser menor quanto menor é a propensão. Além disso, o IS apenas oferece informação na comparação intrassetorial e nada diz a respeito da distribuição intersetorial, ou seja, não oferece medida alguma da relação entre as distribuições setoriais das propensões. Isso significa que embora as distâncias sejam pequenas dentro do mesmo setor, as maiores propensões registradas pelas EMNs podem se localizar em setores diferentes das registradas pelas ENAs. Com o objetivo de minimizar tal deficiência, foram também calculados coeficientes de correlação entre as distribuições setoriais de cada variável analisada para os dois subconjuntos de empresas. Correlações positivas para uma determinada variável indicam que as distribuições das propensões para essa variável estão mais associadas a o setor do que à natureza do capital.

\subsection{Caracterização da atividade inovadora}

Este aspecto trata de identificar se a atividade inovadora desenvolvida por ENAs e EMNs caracteriza-se pela dedicação de recursos, pela realização de $\mathrm{P} \& \mathrm{D}$, pela obtenção de resultados ou pela implementação de inovações de tipo organizacional (inovação de sistemas), assim como pela intensidade inovadora. A intensidade inovadora foi medida por meio da propensão setorial de cada grupo (EMN e ENA) a ser "empresa altamente inovadora", sendo esta definida como a que possui ao menos uma fonte de inovação de origem interna, que realiza tanto inovações de produto quanto de processo e cujas inovaçôes de produto foram significativas no mercado nacional (ARCHIBUGI, CESARATTO; SIRILLI, 1991).

A Tabela 1 apresenta os valores de IS entre as propensões registradas para cada variável por setor. Os setores aparecem agrupados de acordo com a intensidade (alta, média ou baixa) de conteúdo tecnológico.

Em termos gerais, as diferenças de comportamento entre os conjuntos de empresas são reduzidas. As variáveis com as maiores diferenças são as propensões a fazer P\&D $(6,16)$ e a obter resultados $(5,32)$. As propensões são geralmente superiores no grupo das EMNs, sendo que, nas raras exceçôes onde a propensão das ENAs é maior, elas são muito próximas de zero.

6 Por exemplo, porcentagem de firmas inovadoras que realizam P\&D, que obtêm inovação de produto, etc. 
TABELA 1

Caracterização da atividade inovadora, segundo intensidade de conteúdo tecnológico e setores de atividade industrial (Índices de semelhança entre EMN e ENA) Brasil - 2003

\begin{tabular}{|c|c|c|c|c|c|}
\hline \multirow{2}{*}{$\begin{array}{l}\text { Intensidade de conteúdo tecnológico e } \\
\text { setores de atividade industrial }\end{array}$} & \multicolumn{5}{|c|}{ Tipo de atividade } \\
\hline & EAIN & EPD & EDR & EOR & EIS \\
\hline \multicolumn{6}{|l|}{ Baixo } \\
\hline Alimentos & 0,12 & 0,37 & 0,31 & 0,23 & 0,09 \\
\hline Bebidas & 0,00 & 0,25 & 0,01 & 0,36 & 0,06 \\
\hline Fumo & 0,00 & 0,36 & 0,32 & 0,27 & 0,00 \\
\hline Têxteis & 0,00 & 0,16 & 0,16 & 0,19 & 0,08 \\
\hline Confecção & 0,00 & 0,70 & 0,58 & 0,45 & 0,05 \\
\hline Couro e calçado & 0,00 & 0,31 & 0,35 & 0,09 & 0,07 \\
\hline Madeira & 0,01 & 0,04 & 0,11 & 0,04 & 0,11 \\
\hline Papel e artefatos de papel & 0,00 & 0,28 & 0,17 & 0,19 & 0,08 \\
\hline Edição e impressão & 0,00 & 0,02 & 0,07 & 0,30 & 0,07 \\
\hline Minerais não-metálicos & 0,05 & 0,17 & 0,12 & 0,04 & 0,05 \\
\hline Siderurgia & 0,09 & 0,26 & 0,07 & 0,11 & 0,02 \\
\hline Metalurgia e metais não-ferrosos & 0,10 & 0,41 & 0,49 & 0,47 & 0,23 \\
\hline Produtos de metal & 0,01 & 0,30 & 0,17 & 0,24 & 0,05 \\
\hline Artigos do mobiliário & 0,00 & 0,19 & 0,07 & 0,04 & 0,05 \\
\hline Produtos diversos & 0,00 & 0,05 & 0,09 & 0,13 & 0,02 \\
\hline \multicolumn{6}{|l|}{ Médio } \\
\hline Refino de petróleo & 0,00 & 0,25 & 0,30 & 0,55 & 0,01 \\
\hline Produtos químicos & 0,07 & 0,23 & 0,18 & 0,19 & 0,05 \\
\hline Borracha e plástico & 0,00 & 0,05 & 0,09 & 0,09 & 0,07 \\
\hline Máquinas e equipamentos & 0,04 & 0,10 & 0,19 & 0,17 & 0,03 \\
\hline Veículos & 0,19 & 0,53 & 0,15 & 0,17 & 0,13 \\
\hline Peças e acessórios para veículos & 0,01 & 0,03 & 0,06 & 0,04 & 0,01 \\
\hline Outros equipamentos de transporte & 0,12 & 0,08 & 0,14 & 0,22 & 0,07 \\
\hline \multicolumn{6}{|l|}{ Alto } \\
\hline Produtos farmacêuticos & 0,01 & 0,18 & 0,04 & 0,03 & 0,10 \\
\hline $\begin{array}{l}\text { Máquinas para escritório e equipamentos } \\
\text { de informática }\end{array}$ & 0,02 & 0,21 & 0,06 & 0,03 & 0,03 \\
\hline Máquinas, aparelhos e materiais elétricos & 0,03 & 0,11 & 0,07 & 0,04 & 0,01 \\
\hline Material eletrônico básico & 0,00 & 0,07 & 0,01 & 0,25 & 0,07 \\
\hline Aparelhos e equipamentos de comunicações & 0,13 & 0,41 & 0,28 & 0,28 & 0,21 \\
\hline Instrumentos & 0,01 & 0,03 & 0,01 & 0,10 & 0,05 \\
\hline Distância agregada & 1,007 & 6,161 & 4,658 & 5,327 & 1,864 \\
\hline Coeficiente de correlação & 0,071 & 0,446 & 0,529 & 0,407 & $-0,165$ \\
\hline
\end{tabular}

Fonte: IBGE. Pintec 2003. Elaboração própria.

Nota: Empresas altamente inovadoras (EAIN); empresas que fazem P\&D (EPD); empresas que destinam recursos (EDR); empresas que obtêm resultados (EOR); empresas que realizam inovações de sistema (EIS). Em sombreado, os valores onde a propensão das ENAs foi maior que das EMNs. 
Não existem apenas diferenças de comportamento entre EMNs e ENAs na propensão setorial a ser altamente inovadora, dado que, na maioria dos setores, os IS são muito próximos de zero e a distância agregada é 1 . As distâncias maiores (entre 0,10 e 0,19), ainda que pequenas, correspondem a setores em que a entrada do capital estrangeiro é maior e o conteúdo tecnológico, médio-alto (veículos, equipamento de comunicaçôes, outro material de transporte e alimentos).

Apura-se resultado similar na propensão setorial a realizar inovação de sistemas, em que a distância agregada é 1,86 . Os resultados apontam propensões maiores para o grupo das EMNs em grande parte dos setores, com as distâncias mais elevadas (em torno de 0,20$)$ para os setores de metalurgia e equipamentos de comunicações.

As EMNs também apresentam maior propensão a destinar recursos à inovação (para P\&D e outras formas de inovação). No entanto, nesse aspecto, as distâncias entre os dois grupos de empresas são maiores. As mais elevadas para esta propensão (entre 0,30 e 0,60 ) compreendem os setores de baixo conteúdo tecnológico (confecção, metalurgia, couro e calçado, têxtil e alimentos), sempre com propensōes superiores no grupo das EMNs. Nos setores de conteúdo médio e alto, as EMNs se destacam novamente, com maiores distâncias nos setores de refino de petróleo e equipamentos de comunicações (em torno de 0,30).

As diferenças de comportamento inovador entre os dois grupos de empresas são maiores em termos de dedicação de recursos à $\mathrm{P} \& \mathrm{D}$. Novamente, os setores que concentram as maiores diferenças em favor das EMNs são os tradicionais, somando-se aos anteriores os de papel e produtos de metal, com distâncias entre 0,30 e 0,70. No conjunto de conteúdo tecnológico médio e alto, destacam-se os setores de veículos $(0,53)$, refino de petróleo $(0,30)$ e equipamentos de comunicações $(0,41)$.

Em termos de obtenção de resultados, as EMNs mostram claramente propensões mais elevadas que as ENAs. As maiores distâncias concentram-se em refino de petróleo $(0,55)$ e em alguns setores tradicionais, como metalurgia $(0,47)$, confecção $(0,45)$ e edição e impressão $(0,30)$, seguidos de alguns setores de conteúdo tecnológico alto, como equipamentos de comunicações $(0,28)$ e eletrônica básica $(0,25)$.

Em conjunto, o comportamento inovador entre EMNs e ENAs apresenta diferenças maiores em setores de baixo conteúdo tecnológico, com média da soma das distâncias para todas as variáveis ${ }^{7}$ igual a 0,76 , enquanto nos de conteúdo tecnológico médio e alto a média se situa em 0,46 e 0,47 , respectivamente. Os setores com

7 A média da soma das distâncias para cada grupo de setores corresponde a: $1 / n \sum_{i=1}^{5} \sum_{i=1}^{n} S_{i j}$. Dado que o valor máximo dos ISij é 1, o valor máximo da média da soma das distâncias é $5 n / n$, ou seja, o número total de variáveis (cinco). 
comportamento inovador mais distinto são os de confecção, metalurgia, alimentos, veículos, refino de petróleo e equipamentos de telecomunicações.

As distribuições das propensões setoriais entre EMNs e ENAs estão correlacionadas positivamente, com coeficientes significativos (entre 0,4 e 0,5 ) na realização de $P \& D$, na dedicação de recursos e na obtenção de resultados, o que revela a significância dos imperativos setoriais na realização dessas atividades. Já as distribuições da propensão a realizar inovação de sistemas se correlacionam negativamente, registrando-se as maiores propensões a realizar este tipo de inovação nas EMNs nos setores em que as propensões das ENAs são as menores. Tais são os casos de minerais não-metálicos e máquinas, aparelhos e materiais elétricos.

\subsection{Fontes de inovação}

A Pintec 2003 permite identificar fontes de inovação relativas ao tipo de insumo utilizado e à origem do conhecimento. De acordo com o insumo utilizado, foram definidas as propensões a usar recursos exclusivamente internos ${ }^{8}$ (EINI), exclusivamente externos ${ }^{9}$ (EINE) e mistos, ou seja, internos e externos (EMIX) (colunas I, II e III da Tabela 2).

Segundo os dados, as EMNs têm maior propensão a alocar recursos exclusivamente internos e mistos, enquanto as ENAs mostram maior propensão a empregar recursos exclusivamente externos. As diferenças de comportamento inovador em termos de alocação de insumos seguem também esse padrão: as distâncias agregadas são maiores na alocação de recursos exclusivamente internos e mistos do que na de exclusivamente externos.

A distribuição setorial das distâncias mostra o mesmo padrão para ambas as variáveis (recursos exclusivamente internos e mistos), concentrando-se em certos setores de baixo conteúdo tecnológico (alimentos, couro e calçado, confecção, fumo e metalurgia), com IS entre 0,30 e 0,70, e nos setores de médio e alto conteúdo tecnológico, como o de veículos $(0,52-0,53)$ e equipamentos de comunicações $(0,42-0,46)$.

As diferenças entre EMNs e ENAs na alocação de recursos exclusivamente externos concentram-se em bebidas $(0,30)$ e veículos $(0,37)$. Esta variável representa um primeiro indicador de dependência externa. Apesar de a maior dependência nas

8 Se a firma destina recursos a P\&D interna ou emprega em P\&D.

9 Se a firma contrata P\&D externa, adquire máquinas e equipamentos ou patentes, licença ou know-how. 
TABELA 2

Trajetórias tecnológicas, segundo intensidade de conteúdo tecnológico e setores de atividade industria (a) entre EMN e ENA)

Brasil - 2003

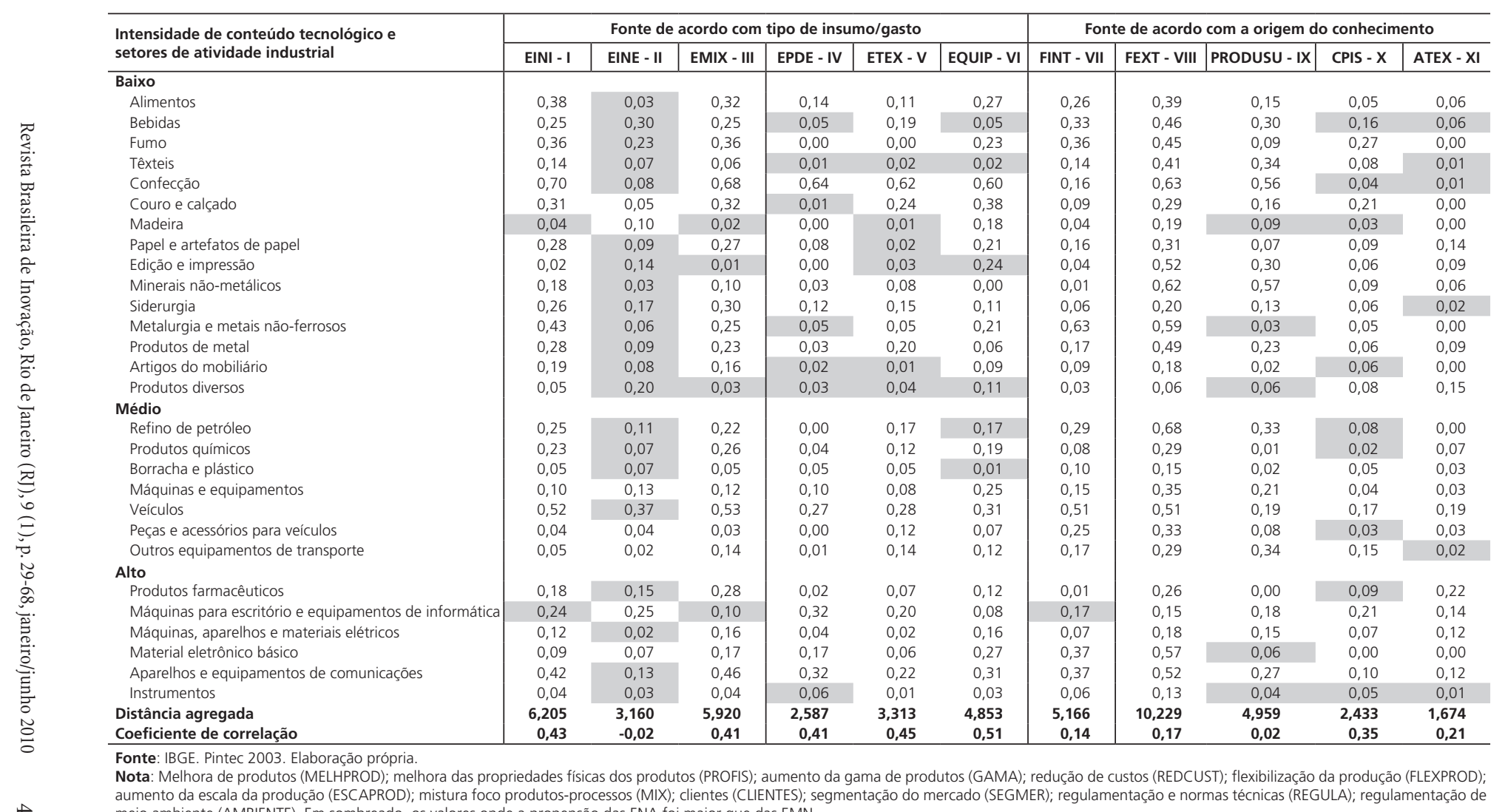


EMNs ser previsível, os dados mostram que as empresas brasileiras têm propensão ainda maior a utilizar recursos tecnológicos de fora da firma. No caso dos setores tradicionais, de baixa oportunidade tecnológica, este balanço seria mais esperado pela dependência de fornecedores ${ }^{10}$ e pela maior propensão das EMNs a utilizar recursos internos da corporação, mas externos à subsidiária. No caso dos setores de conteúdo tecnológico médio e alto, nos quais as oportunidades tecnológicas são maiores, com necessidade de balancear esforços internos e externos para seu melhor aproveitamento (necessidade de criar capacidade de assimilação junto com monitoramento), os dados revelam que as ENAs operam com menor balanço entre recursos internos e externos.

$\mathrm{Na}$ análise por tipo de fonte externa, ${ }^{11}$ as diferenças agregadas entre EMNs e ENAs são relativamente pequenas (colunas IV, $\mathrm{V}$ e VI), sendo maiores no caso da aquisição de máquinas e equipamentos $(4,85)$. Em geral, as ENAs são mais propensas a utilizar fontes externas em setores tradicionais, mas com diferencial muito pequeno. Em sentido contrário, as EMNs mostram maiores propensões em número menor de setores tradicionais e em quase todos aqueles de médio e alto conteúdo tecnológico. Em alguns casos, as distâncias são significativas (superiores a 0,50).

As diferenças na propensão a realizar $\mathrm{P} \& \mathrm{D}$ externa são muito reduzidas na maior parte dos setores (entre 0 e 0,20 ), sendo apenas relevantes no caso de confecção $(0,64)$. Além deste setor, as maiores distâncias se localizam em equipamentos de informática $(0,32)$ e equipamentos de comunicaçōes $(0,32)$.

A aquisição de tecnologia externa tampouco diferencia apreciavelmente as EMNs das ENAs. As diferenças mais significativas se registraram no setor de confeç̧ão $(0,62)$.

As EMNs se apresentam como mais propensas a adquirir máquinas e equipamentos, fundamentalmente nos setores de alto conteúdo tecnológico. No entanto, as diferenças de comportamento em relação às empresas nacionais aglutinam-se nos setores de baixo conteúdo tecnológico, como confecção $(0,60)$ e couro e calçado $(0,38)$, além de outros como veículos $(0,31)$ e equipamentos de comunicações $(0,31)$.

Outra forma de analisar as origens da inovação refere-se às fontes relevantes de conhecimento. Para tanto, foram criadas variáveis sobre as diferentes propensões de outorgar "alta" relevância às fontes internas (Fint), que incluem departamentos

\footnotetext{
10 Supplied dominated na categoria de Pavitt (1984).

11 Não são exclusivamente externas, o que significa que firmas incluídas nestas variáveis podem estar também alocando recursos internos.
} 
de $\mathrm{P} \& \mathrm{D}$; às fontes externas $(\mathrm{Fext})^{12}$; às relações produtor-usuário (Produsu), que incluem fornecedores e clientes; às universidades e centros de capacitação e testes (CPIS) e à aquisição de licenças, patentes e know-how (Atex) (colunas VII, VIII, IX X e XI da Tabela 2).

As EMNs são mais propensas que as ENAs a conceder alta importância às fontes externas em todos os setores, o que aparentemente é uma contradição com o resultado anterior. Este fato se explica pela importância concedida a 'outras empresas do mesmo grupo', consideradas origem externa do conhecimento. Nesta variável, as distâncias agregadas são as mais elevadas, principalmente nos setores de baixo conteúdo tecnológico (confecção, bebidas, fumo, têxteis, edição e impressão, minerais não-metálicos, metalurgia e produtos de metal), com IS entre 0,40 e 0,70, e em outros de conteúdo tecnológico médio e alto, como refino de petróleo, veículos, eletrônica básica e equipamentos de comunicações.

As empresas apresentam também diferenças na propensão a atribuir alta importância às fontes internas, embora em menor medida. As EMNs mostraram mais inclinação para tanto, com maiores diferenças nos setores de fumo $(0,36)$, metalurgia $(0,63)$, veículos $(0,51)$, eletrônica básica $(0,37)$ e equipamentos de comunicações $(0,37)$. Já as ENAs exibem tal propensão no setor de bebidas $(0,33)$, com diferenças significativas em relação às multinacionais.

Com referência ao tipo de origem externa de conhecimento, as maiores diferenças agregadas entre os grupos de empresas concentram-se na importância dada às relaçôes produtor-usuário (com IS de 4,95), sendo quase sempre superior para as EMNs. As maiores distâncias correspondem aos setores de confecção $(0,56)$, minerais não-metálicos $(0,57)$, têxteis $(0,34)$, bebidas $(0,30)$, refino de petróleo $(0,33)$ e outros equipamentos de transporte $(0,34)$.

$\mathrm{Na}$ qualificação da importância das origens, as diferenças para universidades e centros afins (CPIS) e licenças, patentes e know-how (Atex) são muito reduzidas. As ENAs tendem a outorgar alta importância ao conhecimento procedente de CPIS em certos setores (bebidas, confecção, madeira, artigos do mobiliário, refino de petróleo, produtos químicos, peças e acessórios de veículos, produtos farmacêuticos e instrumentos), mas com diferenças muito reduzidas. $\mathrm{O}$ mesmo acontece com relação à origem Atex para os setores de bebida, têxteis, confecção, siderurgia, outros equipamentos de transporte e instrumentos, também com diferenças muito pequenas.

12 Outras empresas do grupo, fornecedores, clientes, concorrentes, consultores, universidades e CPIs, centros de capacitação, institutos de testes, licenças e know-how, conferências e encontros, férias e exposições e redes de informações (perguntas P110 a P121 da Pintec 2003). 
Em termos agregados, o comportamento inovador de EMNs e ENAs é similar, sendo maior a diferença em setores de baixo conteúdo tecnológico, cuja média da soma das distâncias para todas as variáveis ${ }^{13}$ se situa em 1,88 , enquanto nos de conteúdo tecnológico médio e alto os valores apurados são de 1,74 e 1,68, respectivamente. Os setores com as diferenças mais elevadas para o comportamento inovador (soma do IS para todas as variáveis) são os de confecção, veículos, equipamentos de comunicações, bebidas, fumo e metalurgia.

Segundo os coeficientes de correlação, esta ocorre na distribuição setorial das propensões de ENAs e EMNs na dedicação de recursos mistos (internos e externos conjuntamente), na realização de $\mathrm{P} \& \mathrm{D}$ externa, na aquisição de patentes, licenças e know-how e na aquisição de equipamento. Os coeficientes de correlação das propensões quanto às fontes de inovação são positivos, mas muito baixos, independentemente da sua natureza e especialmente no que se refere ao uso de fontes internas e externas e às relações produtor-usuário.

\subsection{Alocação de recursos à inovação}

Para analisar os efeitos de uma provável alocação de recursos externos maior em EMNs do que em ENAs, foram calculados índices de cobertura e de autonomia tecnológica. O índice de cobertura (IC) define-se como a razão entre o somatório dos gastos empreendidos por empresas inovadoras em fontes internas e o somatório dos gastos em fontes externas para cada grupo de empresas. Há predomínio de fontes internas quando IC $>1$, predomínio de fontes externas se IC $<0,70$ e certo equilíbrio entre ambas quando $0,70 \leq \mathrm{IC} \leq 1$.

O índice de autonomia tecnológica (IAT) é calculado como ${ }^{\mathrm{IAT}=} \frac{G_{\text {int }}}{G_{\text {int }}+G_{\text {ext }}}$, onde $\mathrm{Gi}_{\mathrm{nt}}$ representa o gasto em fontes internas e $\mathrm{G}_{\text {ext }}$ o gasto em fontes externas. O IAT assume valores entre 0 e 1 . Se não houver gasto em fontes internas, o IAT será igual a 0 , havendo total dependência tecnológica. Se não houver gasto em fontes externas, o IAT será igual a 1, com total autonomia tecnológica. Foram considerados setores com elevado grau de autonomia aqueles que apresentaram IAT > 0,5; médio grau de autonomia, os que tiveram $0,5 \leq \mathrm{IAT} \leq 0,4$; e setores dependentes aqueles com IAT $<0,4$. As diferenças entre os grupos de empresas são medidas por meio da variação porcentual entre os índices registrados pelas EMNs sobre as ENAs.

13 Dado que são agregados resultados para 11 variáveis, o valor máximo da média da soma das distâncias para cada grupo de setores é igual a 11. 
Tanto as ENAs quanto as EMNs apresentam índices de cobertura inferiores à unidade na maior parte dos setores, ou seja, as fontes internas não cobrem as fontes externas. Este resultado é compatível com o extraído da análise das propensões, confirmando melhor balanço entre fontes internas e externas nas EMNs.

$\mathrm{Na}$ média, as EMNs oferecem taxa de cobertura maior do que as ENAs $(0,768$ e 0,680 , respectivamente), o que significa maior alocação de recursos internos por unidade de recurso externo. Algumas exceções a este comportamento geral formam os IC registrados para o conjunto de ENAs nos setores de fumo, refino de petróleo, equipamentos de informática e outros equipamentos de transporte; e para o conjunto das EMNs nos setores de artigos do mobiliário, minerais não-metálicos, refino de petróleo e instrumentos.

Os setores que apresentaram maior equilíbrio entre os gastos em fontes internas e externas para o conjunto nacional foram os de conteúdo tecnológico alto (produtos farmacêuticos, aparelhos e material elétrico e instrumentos) e médio (veículos). No entanto, no conjunto de EMNs, os setores que mostraram maior equilíbrio de gasto foram os de bebidas, fumo e veículos. Assim, constata-se que o equilíbrio de gasto entre fontes internas e externas, próprio de setores com altas oportunidades tecnológicas, está mais garantido no conjunto nacional do que entre as EMNs. Este resultado é mais consistente com o extraído da análise das fontes de inovação de acordo com a origem do conhecimento.

Os índices de autonomia tecnológica, tanto para ENAs quanto para EMNs, mostraram-se inferiores a 0,5 , para a maior parte dos setores. No conjunto de ENAs existe certa autonomia tecnológica nos setores de fumo, refino de petróleo, outros equipamentos de transporte e em equipamentos de informática e instrumentos, a maioria de setores de conteúdo tecnológico médio ou alto. Já no conjunto de EMNs, mostraram maior autonomia tecnológica os setores de minerais não-metálicos, artigos do mobiliário, refino de petróleo e instrumentos. Assim, embora em média a autonomia tecnológica seja maior nas EMNs do que nas ENAs, estas conseguem melhor desempenho em termos de autonomia em tecnologia nos setores de maior oportunidade tecnológica, nos quais há também maior necessidade de balanço entre fontes internas e externas.

As distâncias setoriais revelam que as variações porcentuais negativas (melhor desempenho das ENAs nos índices de cobertura e autonomia) distribuem-se em 13 dos 28 setores analisados, mas trata-se de distâncias pequenas, enquanto as positivas (melhor desempenho das EMNs nos mesmos índices) são mais elevadas. 
TABELA 3

Índices de cobertura e autonomia tecnológica, segundo setores de atividade industrial

(Distância entre EMN e ENA)

Brasil - 2003

\begin{tabular}{|c|c|c|c|c|c|c|}
\hline \multirow{2}{*}{$\begin{array}{l}\text { Setores de } \\
\text { atividade industrial }\end{array}$} & \multicolumn{2}{|c|}{ ENA } & \multicolumn{2}{|c|}{ EMN } & \multicolumn{2}{|c|}{ Distancia (\%) } \\
\hline & IC & IAT & IC & IAT & Cobertura & Autonomia \\
\hline Alimentos & 0,43 & 0,30 & 0,46 & 0,31 & 7,0 & 3,3 \\
\hline Bebidas & 0,16 & 0,13 & 0,90 & 0,47 & 462,5 & 261,5 \\
\hline Fumo & 1,52 & 0,60 & 0,80 & 0,44 & $-47,4$ & $-26,7$ \\
\hline Têxteis & 0,16 & 0,14 & 0,20 & 0,17 & 25,0 & 21,4 \\
\hline Confecção & 0,31 & 0,23 & 0,46 & 0,31 & 48,4 & 34,8 \\
\hline Couro e calçado & 0,32 & 0,24 & 0,25 & 0,20 & $-21,9$ & $-16,7$ \\
\hline Madeira & 0,22 & 0,18 & 0,29 & 0,22 & 31,8 & 22,2 \\
\hline Papel e artefatos de papel & 0,20 & 0,17 & 0,26 & 0,21 & 30,0 & 23,5 \\
\hline Edição e impressão & 0,13 & 0,12 & 0,00 & 0,00 & $-100,0$ & $-100,0$ \\
\hline Minerais não-metálicos & 0,52 & 0,34 & 1,45 & 0,59 & 178,8 & 73,5 \\
\hline Siderurgia & 0,50 & 0,33 & 0,50 & 0,33 & 0,0 & 0,0 \\
\hline Metalurgia e metais não-ferrosos & 0,25 & 0,20 & 0,60 & 0,37 & 140,0 & 85,0 \\
\hline Produtos de metal & 0,30 & 0,23 & 0,14 & 0,12 & $-53,3$ & $-47,8$ \\
\hline Artigos do mobiliário & 0,33 & 0,25 & 1,30 & 0,57 & 293,9 & 128,0 \\
\hline Produtos diversos & 0,41 & 0,29 & 0,36 & 0,26 & $-12,2$ & $-10,3$ \\
\hline Refino de petróleo & 3,69 & 0,79 & 4,30 & 0,81 & 16,5 & 2,5 \\
\hline Produtos químicos & 0,57 & 0,36 & 0,58 & 0,37 & 1,8 & 2,8 \\
\hline Borracha e plástico & 0,36 & 0,26 & 0,30 & 0,23 & $-16,7$ & $-11,5$ \\
\hline Máquinas e equipamentos & 0,56 & 0,36 & 0,47 & 0,32 & $-16,1$ & $-11,1$ \\
\hline Veículos & 0,81 & 0,45 & 0,91 & 0,48 & 12,3 & 6,7 \\
\hline Peças e acessórios para veículos & 0,41 & 0,29 & 0,55 & 0,35 & 34,1 & 20,7 \\
\hline $\begin{array}{l}\text { Outros equipamentos de } \\
\text { transporte }\end{array}$ & 1,89 & 0,65 & 0,49 & 0,33 & $-74,1$ & $-49,2$ \\
\hline Produtos farmacêuticos & 0,77 & 0,43 & 0,52 & 0,34 & $-32,5$ & $-20,9$ \\
\hline $\begin{array}{l}\text { Máquinas para escritório e } \\
\text { equipamentos de informática }\end{array}$ & 1,53 & 0,60 & 0,35 & 0,26 & $-77,1$ & $-56,7$ \\
\hline $\begin{array}{l}\text { Máquinas, aparelhos e materiais } \\
\text { elétricos }\end{array}$ & 0,76 & 0,43 & 0,48 & 0,33 & $-36,8$ & $-23,3$ \\
\hline Material eletrônico básico & 0,30 & 0,23 & 0,20 & 0,17 & $-33,3$ & $-26,1$ \\
\hline $\begin{array}{l}\text { Aparelhos e equipamentos de } \\
\text { comunicações }\end{array}$ & 0,64 & 0,39 & 0,50 & 0,33 & $-21,9$ & $-15,4$ \\
\hline Instrumentos & 0,99 & 0,50 & 3,88 & 0,79 & 291,9 & 58,0 \\
\hline
\end{tabular}

Fonte: IBGE. Pintec 2003. Elaboração própria.

Nota: Índices de cobertura (IC); índice de autonomia tecnológica (IAT). 
São especialmente relevantes os casos de bebidas, artigos do mobiliário, minerais não-metálicos, metalurgia e instrumentos.

\subsection{Trajetórias tecnológicas}

Os determinantes das trajetórias tecnológicas variam entre os setores. De maneira geral, sua natureza está nos imperativos técnico-produtivos passados, presentes e futuros, na seleção de mercado e na forma e grau em que os setores podem aproveitar novos paradigmas tecnológicos, sendo difícil afirmar que apenas um fator possa ser responsável pelas trajetórias seguidas pelas firmas dentro de um mesmo setor (KLEVORICK et al., 1995). Por estas razóes, espera-se que o comportamento de empresas do mesmo setor na definição do foco e da trajetória tecnológica não seja muito diferente, especialmente as que atuam em países capturadores, onde as atividades desenvolvidas pelas EMNs consistem na adaptação das suas competências às demandas dos mercados locais.

A Tabela 4 mostra esse resultado. As informaçōes sobre trajetórias tecnológicas foram organizadas em cinco grupos: orientadas ao desenvolvimento de produtos (Grupo I - Produtos), ao desenvolvimento de processos (Grupo II - Processo), ao desenvolvimento de ambos, com foco misto (Grupo III - Mix), às especificidades dos mercados (Grupo IV - Mercado) e as que são conduzidas por normas, especificamente técnicas e de meio ambiente (Grupo V - Normas). Sobre um valor máximo de 28, as distâncias agregadas para todos os setores em cada variável são sempre inferiores a cinco. Os maiores valores se localizam no desenvolvimento de produtos e mercados (entre 4 e, aproximadamente, 5), sendo praticamente imperceptíveis no caso de foco misto e muito reduzidos nos casos de processos e de direcionamento baseado em normas.

As similaridades também se mantêm por setores e grupos de setores. A média da soma das distâncias para todas as variáveis ${ }^{14}$ é de 1,62 no grupo de setores de conteúdo tecnológico alto, sendo um pouco menor nos de conteúdo tecnológico médio e baixo (1,52 e 1,40, respectivamente). Os setores com comportamento inovador mais distinto (soma do IS para todas as variáveis) são os de equipamentos de comunicações, veículos e metalurgia, com valores médios variando entre 2,5 e 4,0.

A trajetória tecnológica voltada ao desenvolvimento de produtos revela que apenas no setor de equipamentos de comunicações as diferenças entre empresas

14 Neste caso, o valor máximo da média da soma das distâncias para as 11 variáveis é igual a 11. 
TABELA 4

Trajetórias tecnológicas, segundo intensidade de conteúdo tecnológico e setores de atividade industrial (Índices de semelhança entre EMN e ENA)

\begin{tabular}{|c|c|c|c|c|c|c|c|c|c|c|c|}
\hline $\begin{array}{l}\text { Intensidade de conteúdo tecnológico e } \\
\text { setores de atividade industrial }\end{array}$ & \multicolumn{3}{|c|}{ I. Produtos } & \multicolumn{3}{|c|}{ II. Processos } & \begin{tabular}{|l|} 
III. Mix \\
FOCOMIX
\end{tabular} & \multicolumn{2}{|c|}{ IV. Mercados } & \multicolumn{2}{|c|}{ V. Normas } \\
\hline \multicolumn{12}{|l|}{ Baixo } \\
\hline Alimentos & 0,14 & 0,11 & 0,17 & 0,09 & 0,08 & 0,16 & 0,07 & 0,18 & 0,21 & 0,13 & 0,08 \\
\hline Fumo & 0,27 & 0,27 & 0,00 & 0,27 & 0,00 & 0,36 & 0,00 & 0,12 & 0,55 & 0,00 & 0,27 \\
\hline Têxteis & 0,22 & 0,22 & 0,26 & 0,00 & 0,20 & 0,06 & 0,01 & 0,30 & 0,16 & 0,12 & 0,09 \\
\hline Confecção & 0,55 & 0,54 & 0,02 & 0,00 & 0,00 & 0,06 & 0,05 & 0,53 & 0,60 & 0,01 & 0,05 \\
\hline Couro e calçado & 0,22 & 0,19 & 0,08 & 0,05 & 0,21 & 0,19 & 0,04 & 0,15 & 0,09 & 0,25 & 0,21 \\
\hline Madeira & 0,10 & 0,09 & 0,07 & 0,08 & 0,15 & 0,04 & 0,05 & 0,03 & 0,14 & 0,17 & 0,23 \\
\hline Minerais não-metálicos & 0,03 & 0,04 & 0,08 & 0,05 & 0,05 & 0,05 & 0,05 & 0,20 & 0,07 & 0,09 & 0,06 \\
\hline Siderurgia & 0,08 & 0,08 & 0,24 & 0,10 & 0,06 & 0,11 & 0,03 & 0,16 & 0,18 & 0,13 & 0,07 \\
\hline Metalurgia e metais não-ferrosos & 0,28 & 0,19 & 0,34 & 0,05 & 0,04 & 0,34 & 0,04 & 0,25 & 0,43 & 0,35 & 0,35 \\
\hline Produtos de metal & 0,07 & 0,13 & 0,08 & 0,05 & 0,07 & 0,11 & 0,06 & 0,15 & 0,08 & 0,11 & 0,02 \\
\hline Artigos do mobiliário & 0,01 & 0,04 & 0,11 & 0,13 & 0,03 & 0,14 & 0,09 & 0,02 & 0,11 & 0,09 & 0,10 \\
\hline Produtos diversos & 0,10 & 0,10 & 0,08 & 0,05 & 0,06 & 0,06 & 0,05 & 0,04 & 0,06 & 0,06 & 0,02 \\
\hline \multicolumn{12}{|l|}{ Médio } \\
\hline Refino de petróleo & 0,52 & 0,32 & 0,39 & 0,00 & 0,05 & 0,08 & 0,00 & 0,36 & 0,32 & 0,05 & 0,11 \\
\hline Produtos químicos & 0,17 & 0,10 & 0,13 & 0,14 & 0,13 & 0,10 & 0,09 & 0,09 & 0,18 & 0,11 & 0,13 \\
\hline Produtos farmacêuticos & 0,01 & 0,11 & 0,10 & 0,02 & 0,07 & 0,14 & 0,04 & 0,11 & 0,04 & 0,04 & 0,30 \\
\hline Máquinas para escritório e equipamentos de informática & 0,22 & 0,56 & 0,10 & 0,19 & 0,04 & 0,14 & 0,20 & 0,19 & 0,01 & 0,17 & 0,19 \\
\hline Máquinas, aparelhos e materiais elétricos & 0,03 & 0,05 & 0,04 & 0,06 & 0,07 & 0,07 & 0,03 & 0,13 & 0,03 & 0,14 & 0,02 \\
\hline Material eletrônico básico & 0,23 & 0,01 & 0,26 & 0,05 & 0,05 & 0,08 & 0,07 & 0,06 & 0,03 & 0,12 & 0,07 \\
\hline Aparelhos e equipamentos de comunicaçoes & 0,54 & 0,48 & 0,41 & 0,20 & 0,31 & 0,31 & 0,19 & 0,42 & 0,55 & 0,32 & 0,26 \\
\hline Instrumentos & 0,20 & 0,22 & 0,06 & 0,03 & 0,04 & 0,14 & 0,04 & 0,06 & 0,15 & 0,07 & 0,05 \\
\hline Distância agregada & 4,959 & 4,621 & 4,080 & 2,442 & 2,626 & 3,665 & 1,709 & 4,781 & 4,952 & 3,917 & 3,558 \\
\hline Coeficiente de correlação & 0,29 & $-0,12$ & 0,38 & 0,18 & 0,43 & 0,05 & 0,45 & 0,21 & 0,07 & 0,24 & 0,30 \\
\hline
\end{tabular}

Nota: Melhora de produtos (MELHPROD); melhora das propriedades físicas dos produtos (PROFIS); aumento da gama de produtos (GAMA); redução de custos (REDCUST); flexibilização da produçăo (FLEXPROD); aumento da escala da produção (ESCAPROD); mistura foco produtos-processos (MIX); clientes (CLIENTES); segmentaçăo do mercado (SEGMER); regulamentação e normas técnicas (REGULA); regulamentaçăo de 
multinacionais e estrangeiras podem ter relevância (entre 0,4 e 0,5 para as três trajetórias analisadas). Quanto à melhora genérica de produtos, as maiores distâncias se localizam nos setores de confecção $(0,55)$ e refino de petróleo $(0,52)$, além do setor de equipamentos de comunicação já citado.

No que se refere às melhoras relativas às propriedades físicas dos produtos, as distâncias relevantes aparecem nos setores de confecção $(0,54)$ e equipamentos de informática $(0,56)$. Não se observam diferenças importantes entre EMNs e ENAs nas trajetórias voltadas ao desenvolvimento de produtos com foco no aumento de sua gama.

De maneira geral, as EMNs são mais propensas a se pautarem por esse tipo de trajetória, sendo as exceçōes as indústrias de instrumentos e produtos diversos, em que as ENAs registram propensões maiores nas três trajetórias relativas a produtos que foram estudadas.

A trajetória voltada para o desenvolvimento de processos não mostra a existência de diferenças de comportamento relevantes em nenhum setor, dado que os valores de IS são inferiores a 0,4. A necessidade de redução de custos, flexibilização de produção e de aumento na escala da produção parecem nortear o direcionamento dos esforços tecnológicos de EMNs e ENAs com a mesma intensidade. Novamente, as empresas nacionais registram menores propensōes que as multinacionais neste tipo de trajetória. É relevante observar que para as mudanças na escala de produção as ENAs revelam maiores propensões em oito setores (bebidas, confecção, refino de petróleo, siderurgia, produtos de metal, eletrônica básica, artigos do mobiliário e produtos diversos). Em produtos de metal, a maior propensão também se registra para a redução de custos e vlexibilização da produção. Nos setores de bebidas, produtos de metal, produtos diversos e refino de petróleo, registram-se ainda as maiores propensōes das ENAs na flexibilização da produção.

O foco misto da trajetória tecnológica (voltado a processos e produtos simultaneamente) também registra pequenas diferenças de comportamento. No entanto, as ENAs exibem maior propensão média em 13 dos 28 setores analisados, compreendendo os de bebidas, todo o complexo da indústria têxtil e de couro e calçado, madeira, produtos farmacêuticos, borracha e plástico, metalurgia, produtos de metal, eletrônica básica, instrumentos e outros equipamentos de transporte.

No que se refere à trajetória tecnológica focada no mercado, existem diferenças significativas entre EMNs e ENAs nos setores de confecção e equipamentos de comunicaçōes, tanto para o atendimento às especificidades dos clientes quanto para a segmentação de mercado. Não há outros setores em que as necessidades dos 
clientes determinem diferenças substanciais de comportamento entre os grupos de empresas. Já na segmentação de mercado encontram-se diferenças médias em torno de 0,4 nos setores de metalurgia, fumo e veículos.

Quando se trata de segmentação de mercado, as EMNs mostram maiores propensões em praticamente todos os setores, salvo em eletrônica básica, instrumentos e produtos diversos. Em contraste, para o foco nos clientes as ENAs mostram maior propensão em número maior de setores, entre eles os citados anteriormente e os de fumo, couro e calçado, artigos do mobiliário, papel, metalurgia, refino de petróleo, produtos químicos e borracha e plásticos. Assim, as trajetórias tecnológicas orientadas ao mercado (segmentação e necessidades dos clientes) parecem mostrarse mais relevantes para as ENAs nos setores de eletrônica básica, instrumentos e produtos diversos.

As trajetórias tecnológicas definidas pelas normas técnicas e de meio ambiente tampouco levam a diferenças de comportamento relevantes entre EMNs e ENAs, sendo os casos que revelam maiores diferenças os dos setores de veículos $(0,40)$ e metalurgia $(0,32)$, em que as EMNs detêm maior propensão a se pautarem pela normalização técnica.

Em termos gerais, as EMNs se mostram mais propensas a se orientarem por normas técnicas e de meio ambiente, excetuando-se os casos de bebidas, confecção e instrumentos, setores em que as ENAs mostram maior propensão.

Dado que as trajetórias tecnológicas têm forte componente setorial, isto é, representam imperativos na determinação do caminho tomado pela mudança tecnológica em firmas que pertencem ao mesmo setor, também se espera que as relaçôes intersetoriais se distribuam de forma similar entre EMNs e ENAs. Os índices de correlação revelam este resultado, dado que as distribuições entre setores estão positivamente relacionadas para todas as variáveis ligadas às trajetórias tecnológicas que foram contempladas, o que significa tendência a mostrar as maiores e menores propensões nos mesmos setores. $\mathrm{O}$ único caso de correlação negativa se registra na variável relativa a melhora nas propriedades físicas dos produtos.

Em geral, os coeficientes de correlação são baixos, entretanto, mostram-se significativos nas trajetórias de flexibilização da produção e foco misto de processos e produtos.

\subsection{Processos de aprendizagem}

Os processos de aprendizado compreendem aquisição e acumulação de conhecimento (ARCHIBUGI, 1991, p. 31). São basicamente internos à firma, pois estão 
fortemente vinculados à experiência, à quantidade e qualidade do conhecimentobase das organizações e às suas formas organizacionais (GARCÍA-GARCÍA, 1995). A especificidade de cada organização na composição desses fatores introduz uma grande diversidade de processos de aprendizagem, que se traduz em direções distintas e ritmos diferenciados de mudança técnica na empresa. A habilidade para aprender difere entre empresas devido às suas especificidades em termos de competências internas, localização, programas de treinamento, gastos em P\&D ou atitudes ante a conduta das rivais.

Existem numerosos tipos de aprendizagem que dificilmente acontecem de forma isolada. Pelo contrário, eles costumam estar estreitamente inter-relacionados. A possibilidade de combinar distintas formas de aprendizagem depende do tipo de atividade que a empresa desenvolve (competências produtivas), dos requerimentos tecnológicos relativos ao seu conhecimento-base (competências tecnológicas) e das interações com o ambiente externo (MALERBA, 1992).

A combinação de distintos tipos de aprendizagem leva a pensar que haveria certos padróes setoriais de acordo com dois elementos (LEVIN et al., 1987; LEVIN, 1988; MALERBA; ORSENIGO, 1990; PATEL; PAVITT, 1995): a sensibilidade de cada setor às mudanças produzidas nas oportunidades tecnológicas setoriais; as peculiaridades dos cenários setoriais em termos de produção e comercialização dos produtos (relaçôes com fornecedores e usuários, internalização ou externalização dos processos de busca, cooperação ou rivalidade nos mercados, vínculos com o sistema científico ou a sensibilidade às mudanças na regulação).

Dessa forma, aceitando que os imperativos setoriais definem as formas dominantes de aprendizado na firma, não seria previsível encontrar grandes diferenças entre empresas que operam no mesmo setor, mesmo com diferente natureza de seu capital. Em contrapartida, as firmas definem seus processos de aprendizado com base em formas organizativas e composição de experiências específicas e, na medida em que houvesse diferenças desse tipo entre EMNs e ENAs, os processos de aprendizagem poderiam também ser diferentes.

A partir dos dados da Pintec 2003 foram definidos quatro tipos de aprendizado seguindo a taxonomia de Malerba (1992) (ver Anexo 1): o aprendizado derivado das atividades de P\&D (learning by search); o derivado dos processos de formação ou treinamento (learning by learn); o que resulta da interação da empresa com o exterior, das relaçôes com fornecedores e usuários na cadeia produtiva e da cooperação (learning by interacting); e o realizado sobre os avanços na ciência e tecnologia por meio da contratação de atividades de pesquisa de outras empresas 
ou de universidades e centros públicos de pesquisa (learning by hiring), através do que se cria um mecanismo seletivo na incorporação de campos científicos ou tecnológicos emergentes.

A análise das formas relevantes de aprendizado em EMNs e ENAs revela que as diferenças entre os dois tipos de firmas dentro de cada setor são muito pequenas, prevalecendo a ideia dos imperativos setoriais na definição dos processos de aprendizado. As maiores distâncias correspondem à propensão a outorgar importância alta nas variáveis que definem o learning by interacting.

No learning by search, as maiores distâncias (entre 0,3 e 0,5) compreendem os setores de refino de petróleo, veículos e equipamentos de comunicaçôes; no learning by learn, as maiores diferenças também se encontram nos setores de veículos e equipamentos de comunicaçôes, juntamente com o setor de couro e calçados. Com o mesmo intervalo se registram as maiores distâncias no learing by interacting nos setores de confecção, fumo, minerais não-metálicos, equipamentos de informática e equipamentos de comunicações. No learning by hiring não se apreciam diferenças significativas em nenhum setor.

A média da soma das distâncias para todas as variáveis dentro de cada grupo de setores de alto, médio e baixo conteúdo tecnológico ${ }^{15}$ revela escassas diferenças, sendo maiores no grupo de conteúdo médio $(0,58)$, seguido pelos grupos de conteúdo alto $(0,55)$ e baixo $(0,52)$.

No conjunto, as EMNs se mostram mais propensas a conceder alta importância a cada uma das fontes de aprendizado, porém com algumas exceções interessantes. No aprendizado pela contratação (hiring), as ENAs atribuíram importância elevada, com maior proporção que as EMNs em oito setores, e, no aprendizado pela interação (interacting), em sete setores. Nos de madeira e instrumentos, as empresas nacionais outorgaram maior importância que as multinacionais ao aprendizado pela busca, interação e subcontratação; no caso do setor mobiliário, as ENAs imputaram maior importância que as EMNs ao aprendizado pela formação e treinamento, interação e subcontratação.

Finalmente, os índices de correlação com sinal positivo confirmam que os determinantes setoriais são mais fortes que as formas organizacionais das firmas na definição de seus padrões de aprendizado, estando as maiores e menores propensōes localizadas nos mesmos setores, tanto no grupo das ENAs quanto no das EMNs. Estes coeficientes se mostram mais significativos nos casos do aprendizado pela busca e pela formação e treinamento.

15 O valor máximo da média da soma das distâncias para cada grupo de setores é igual a 4. 
TABELA 5

Formas típicas de aprendizagem, segundo intensidade de conteúdo tecnológico e setores de atividade industrial (Índices de semelhança entre EMN e ENA) Brasil - 2003

\begin{tabular}{|c|c|c|c|c|}
\hline $\begin{array}{l}\text { Intensidade de conteúdo tecnológico e } \\
\text { setores de atividade industrial }\end{array}$ & SEARCH & LEARN & INTERACT & HIRING \\
\hline \multicolumn{5}{|l|}{ Baixo } \\
\hline Alimentos & 0,27 & 0,14 & 0,13 & 0,05 \\
\hline Bebidas & 0,00 & 0,02 & 0,14 & 0,16 \\
\hline Fumo & 0,27 & 0,00 & 0,36 & 0,27 \\
\hline Têxteis & 0,10 & 0,05 & 0,29 & 0,06 \\
\hline Confecção & 0,00 & 0,03 & 0,51 & 0,05 \\
\hline Couro e calçado & 0,01 & 0,36 & 0,10 & 0,20 \\
\hline Madeira & 0,03 & 0,21 & 0,01 & 0,03 \\
\hline Papel e artefatos de papel & 0,21 & 0,15 & 0,29 & 0,12 \\
\hline Edição e impressão & 0,01 & 0,04 & 0,25 & 0,08 \\
\hline Minerais não-metálicos & 0,09 & 0,05 & 0,51 & 0,08 \\
\hline Siderurgia & 0,24 & 0,13 & 0,14 & 0,09 \\
\hline Metalurgia e metais não-ferrosos & 0,16 & 0,24 & 0,04 & 0,05 \\
\hline Produtos de metal & 0,04 & 0,09 & 0,29 & 0,21 \\
\hline Artigos do mobiliário & 0,22 & 0,07 & 0,06 & 0,08 \\
\hline Produtos diversos & 0,07 & 0,03 & 0,08 & 0,09 \\
\hline \multicolumn{5}{|l|}{ Médio } \\
\hline Refino de petróleo & 0,31 & 0,05 & 0,29 & 0,13 \\
\hline Produtos químicos & 0,17 & 0,19 & 0,06 & 0,02 \\
\hline Borracha e plástico & 0,05 & 0,06 & 0,06 & 0,04 \\
\hline Máquinas e equipamentos & 0,07 & 0,19 & 0,16 & 0,05 \\
\hline Veículos & 0,51 & 0,37 & 0,22 & 0,16 \\
\hline Peças e acessórios para veículos & 0,10 & 0,03 & 0,07 & 0,03 \\
\hline Outros equipamentos de transporte & 0,14 & 0,17 & 0,24 & 0,10 \\
\hline \multicolumn{5}{|l|}{ Alto } \\
\hline Produtos farmacêuticos & 0,15 & 0,09 & 0,13 & 0,12 \\
\hline Máquinas para escritório e equipamentos de informática & 0,10 & 0,05 & 0,32 & 0,19 \\
\hline Máquinas, aparelhos e materiais elétricos & 0,08 & 0,12 & 0,10 & 0,06 \\
\hline Material eletrônico básico & 0,19 & 0,11 & 0,13 & 0,00 \\
\hline Aparelhos e equipamentos de comunicações & 0,30 & 0,43 & 0,32 & 0,10 \\
\hline Instrumentos & 0,01 & 0,01 & 0,11 & 0,07 \\
\hline Distância agregada & 3,914 & 3,479 & 5,431 & 2,699 \\
\hline
\end{tabular}




\subsection{Resultados de inovação: processos e produtos}

A comparação do comportamento inovador entre EMNs e ENAs em termos de obtenção de resultados revela que as primeiras são mais propensas a obter qualquer tipo de resultado de inovação, independentemente de como seja este definido: como inovação de produto ou de processo, como a obtenção de inovações radicais ou incrementais ${ }^{16}$ ou ainda como patenteamento ou obtenção de receitas pela comercialização de inovaçôes. Nos casos em que as ENAs mostram propensão maior, o IS é muito próximo de zero, ou seja, as diferenças são muito pequenas.

A esta regra geral surgem algumas exceçôes. $\mathrm{O}$ setor da madeira se apresenta atípico porque as suas ENAs se mostram mais propensas a obter resultados de inovação. Produtos diversos exibem maior tendência a obter resultados de inovação nas ENAs em cinco das seis definições utilizadas para resultados e, para instrumentos, em quatro das seis categorias.

Outro achado interessante é que as ENAs de um grande número de setores se mostram mais propensas a registrar patentes do que as EMNs, fundamentalmente em setores de conteúdo tecnológico baixo, em que a propensão a patentear é menor, e em alguns setores de conteúdo tecnológico elevado, como nos casos de eletrônica básica e instrumentos. Esta observação pode ser explicada pelo fato de as EMNs terem uma estratégia patenteadora global, de forma que os resultados obtidos por subsidiárias no Brasil podem acabar sendo patenteadas por subsidiárias da mesma empresa em outro lugar do mundo.

Por grupos de setores, a média da soma das distâncias para as seis variáveis ${ }^{17}$ revela escassas diferenças, sendo elas maiores no grupo de conteúdo médio $(1,06)$, seguido pelos de conteúdo alto $(1,05)$ e baixo $(1,00)$ (Tabela 6). A análise setorial mostra comportamentos distintos entre EMNs e ENAs em refino de petróleo, equipamentos de comunicações, metalurgia e confecção.

Como esperado, as diferenças entre EMNs e ENAs na propensão a realizar inovação de processo e de produto são reduzidas na maior parte dos setores, dado que se mostram mais relevantes os imperativos tecnológicos, produtivos e de mercado,

16 Empresa que realiza inovações radicais é aquela que introduziu um produto ou processo novo para o mercado nacional, exportou ou obteve receita pela comercialização de novos produtos para o mercado nacional ou depositou patentes ou tem solicitado patentes no exterior ou no exterior e no Brasil. Empresa que realizou inovações incrementais é aquela que introduziu inovações de produto ou processo já existente no mercado nacional, exportou ou obteve receita pela comercialização de inovações já existentes no mercado nacional ou depositou patentes ou tem patentes em vigor no Brasil.

17 O valor máximo da média da soma das distâncias para cada grupo de setores é igual a 6. 
TABELA 6

Resultados da inovação, segundo intensidade de conteúdo tecnológico e setores de atividade industrial (Índices de semelhança entre EMN e ENA) Brasil - 2003

\begin{tabular}{|c|c|c|c|c|c|c|}
\hline $\begin{array}{l}\text { Intensidade de conteúdo } \\
\text { tecnológico e setores de } \\
\text { atividade industrial }\end{array}$ & EIPROD & EIPROC & RADIC & INCR & EIPATEN & EIREC \\
\hline \multicolumn{7}{|l|}{ Baixo } \\
\hline Alimentos & 0,28 & 0,19 & 0,25 & 0,17 & 0,12 & 0,29 \\
\hline Bebidas & 0,38 & 0,16 & 0,22 & 0,30 & 0,12 & 0,38 \\
\hline Fumo & 0,12 & 0,33 & 0,12 & 0,24 & 0,00 & 0,12 \\
\hline Têxteis & 0,05 & 0,19 & 0,05 & 0,13 & 0,02 & 0,06 \\
\hline Confecção & 0,12 & 0,51 & 0,54 & 0,43 & 0,00 & 0,12 \\
\hline Couro e calçado & 0,22 & 0,14 & 0,21 & 0,10 & 0,01 & 0,19 \\
\hline Madeira & 0,15 & 0,05 & 0,16 & 0,12 & 0,02 & 0,15 \\
\hline Papel e artefatos de papel & 0,18 & 0,23 & 0,12 & 0,13 & 0,30 & 0,18 \\
\hline Edição e impressão & 0,07 & 0,25 & 0,36 & 0,28 & 0,07 & 0,07 \\
\hline Minerais não-metálicos & 0,02 & 0,04 & 0,06 & 0,08 & 0,05 & 0,02 \\
\hline Siderurgia & 0,29 & 0,10 & 0,22 & 0,11 & 0,28 & 0,29 \\
\hline Metalurgia e metais não-ferrosos & 0,42 & 0,24 & 0,42 & 0,19 & 0,08 & 0,44 \\
\hline Produtos de metal & 0,37 & 0,08 & 0,22 & 0,21 & 0,09 & 0,38 \\
\hline Artigos do mobiliário & 0,04 & 0,02 & 0,10 & 0,04 & 0,02 & 0,04 \\
\hline Produtos diversos & 0,03 & 0,08 & 0,01 & 0,10 & 0,03 & 0,03 \\
\hline \multicolumn{7}{|l|}{ Médio } \\
\hline Refino de petróleo & 0,60 & 0,10 & 0,58 & 0,31 & 0,00 & 0,60 \\
\hline Produtos químicos & 0,14 & 0,15 & 0,23 & 0,14 & 0,14 & 0,13 \\
\hline Borracha e plástico & 0,15 & 0,12 & 0,05 & 0,14 & 0,01 & 0,15 \\
\hline Máquinas e equipamentos & 0,08 & 0,20 & 0,09 & 0,18 & 0,08 & 0,07 \\
\hline Veículos & 0,32 & 0,30 & 0,27 & 0,10 & 0,30 & 0,35 \\
\hline Peças e acessórios para veículos & 0,01 & 0,12 & 0,17 & 0,07 & 0,01 & 0,00 \\
\hline $\begin{array}{l}\text { Outros equipamentos de } \\
\text { transporte } \\
\text { Alto }\end{array}$ & 0,21 & 0,17 & 0,15 & 0,19 & 0,01 & 0,25 \\
\hline \multirow{2}{*}{$\begin{array}{l}\text { Produtos farmacêuticos } \\
\text { Máquinas para escritório e } \\
\text { equipamentos de informática }\end{array}$} & 0,10 & 0,20 & 0,12 & 0,05 & 0,13 & 0,07 \\
\hline & 0,10 & 0,29 & 0,00 & 0,04 & 0,04 & 0,15 \\
\hline $\begin{array}{l}\text { Máquinas, aparelhos e materiais } \\
\text { elétricos }\end{array}$ & 0,13 & 0,13 & 0,12 & 0,12 & 0,12 & 0,13 \\
\hline Material eletrônico básico & 0,29 & 0,37 & 0,15 & 0,23 & 0,06 & 0,32 \\
\hline $\begin{array}{l}\text { Aparelhos e equipamentos de } \\
\text { comunicações }\end{array}$ & 0,45 & 0,41 & 0,43 & 0,34 & 0,08 & 0,38 \\
\hline Instrumentos & 0,22 & 0,15 & 0,03 & 0,08 & 0,02 & 0,22 \\
\hline Distância agregada & 5,543 & 5,334 & 5,454 & 4,619 & 2,240 & 5,580 \\
\hline
\end{tabular}

Fonte: IBGE. Pintec 2003. Elaboração própria.

Nota: Inovação de produto (EIPROD); inovação de processo (EIPROC); inovação radical (RADIC); inovação incremental (INCR); propensão a patentear (EIPATENT); propensão a obter receita pela comercialização de inovações (EIREC). Em sombreado, os valores onde a propensão das ENAs foi maior que das EMNs. 
em detrimento da natureza do capital das firmas. As distâncias mais relevantes na tendência a obter inovação de produto correspondem a refino de petróleo $(0,60)$, equipamentos de comunicações $(0,45)$, metalurgia $(0,42)$, bebidas $(0,38)$ e produtos de metal $(0,37)$; na propensão a realizar inovação de processo, as distâncias maiores se concentraram em confecção $(0,51)$ e equipamentos de comunicações $(0,41)$.

As diferenças agregadas entre EMNs e ENAs na propensão a realizar inovação radical são ligeiramente superiores às correspondentes a inovação incremental e, em qualquer caso, são reduzidas para a maior parte dos setores. As maiores diferenças encontradas para o primeiro caso compreendem os setores de refino de petróleo $(0,58)$, confecção $(0,54)$, equipamentos de comunicações $(0,43)$ e metalurgia $(0,42)$. Os três primeiros setores também registram as maiores distâncias na propensão a realizar inovações de tipo incremental, porém em ordem diversa: confecção $(0,43)$, equipamentos de comunicações $(0,34)$ e refino de petróleo $(0,31)$.

As diferenças na propensão a patentear são muito reduzidas em termos agregados, o que significa que a internacionalização da atividade inovadora das empresas estrangeiras que operam no Brasil não inclui estratégias de patenteamento globais para manter liderança tecnológica no mercado nacional, mas provavelmente para manter sua liderança em mercados exteriores.

As EMNs mostram maior propensão a obter receita pela comercialização de inovaçôes, com IS especialmente elevado em refino de petróleo $(0,60)$ e metalurgia $(0,44)$ e com IS médio em bebidas $(0,38)$, produtos de metal $(0,38)$ e equipamentos de comunicações $(0,38)$. Os setores onde as ENAs apresentam maior propensão são tradicionais (fumo, confecção, madeira e produtos diversos e instrumentos).

Os coeficientes de correlação também corroboram a importância dos imperativos setoriais como determinantes da atividade inovadora em detrimento de aspectos relacionados com a natureza da firma, dado que em todos os casos se mostram positivos. Tais coeficientes foram especialmente significativos na inovação de produto, processo, inovação incremental e obtenção de receita por comercialização de inovaçoes, com valores entre 0,40 e 0,45 .

\section{Considerações finais}

Este estudo propôs identificar diferenças de comportamento inovador entre EMNs e ENAs sob as seguintes hipóteses:

- as EMNs deveriam registrar maior ritmo de mudança tecnológica do que as ENAs; 
- as EMNs deveriam registrar maior dependência externa refletida na maior propensão a utilizar fontes externas;

- as trajetórias tecnológicas, por dependerem de imperativos tecnoprodutivos setoriais, não deveriam levar a diferenças de comportamento entre EMNs e ENAs;

- os padrōes de aprendizado, embora também determinados por imperativos setoriais, poderiam ser diferentes em virtude de formas organizacionais da firmas específicas, o que poderia conduzir a um diferente comportamento entre EMNs e ENAs, sem definição da forma em que isso ocorreria;

- o tipo de P\&D realizado pelas EMNs em países seguidores estaria mais propenso a ser adaptativo (duplicação de competências) do que de especialização, e tenderia a apresentar maior propensão a registrar resultados da inovação do tipo incremental, em vez de radical.

O trabalho utilizou as informaçōes disponíveis na Pintec 2003 para calcular índices de semelhança que medem as distâncias observadas entre EMNs e ENAs nas propensōes registradas para cada variável e para cada setor, com desagregação de três dígitos da CNAE. Também foram calculados coeficientes de correlação entre as distribuições das propensōes para observar o grau de relação intersetorial.

A análise comparativa da intensidade e atividade inovadora para os dois conjuntos de empresas mostra que as EMNs são, em geral, mais propensas a destinar recursos, a obter resultados e a introduzir inovação de sistemas. Entretanto, a intensidade inovadora, medida como a propensão a ser altamente inovadora, é muito semelhante à das ENAs. As maiores diferenças se localizam no grupo de setores de baixo conteúdo tecnológico.

As diferenças de comportamento em termos de utilização de fontes são maiores, como esperado. Em termos de alocação de recursos, as ENAs são mais propensas a utilizar fontes externas exclusivamente, o que revela o escasso esforço interno em inovação realizado pelas firmas brasileiras. Este resultado se vê reforçado pelo registro de maior cobertura e autonomia tecnológica nas EMNs. No entanto, estas são mais propensas a indicar as fontes externas como relevantes para seus processos de inovação e se revelam com maior autonomia e cobertura tecnológica na maior parte dos setores de conteúdo tecnológico médio e alto, nos quais é necessário maior balanço entre fontes internas e externas.

As trajetórias tecnológicas das firmas parecem estar definidas por imperativos setoriais, sendo muito reduzidas as diferenças de comportamento entre EMNs e 
ENAs. As maiores distâncias compreendem as trajetórias voltadas para o desenvolvimento de produtos, especialmente em confecção, refino de petróleo e equipamentos de informática. O coeficiente de correlação negativo registrado na trajetória focada nas propriedades físicas dos produtos indica que este não é um caso que responda a um imperativo setorial.

Os tipos relevantes de aprendizado também parecem responder mais a imperativos setoriais do que às formas organizacionais das firmas, dado que não há diferenças relevantes na importância outorgada aos distintos tipos de aprendizado, o que é corroborado pelos coeficientes de correlação. As maiores diferenças estão no aprendizado pela interação com clientes e fornecedores, especialmente relevantes no setor de confecção.

Sobre o tipo de resultado, a análise mostra que, de acordo com a composição do capital, novamente os imperativos setoriais são mais determinantes que a organização da firma. As diferenças agregadas na propensão a inovar produtos ou processos são muito similares e os coeficientes de correlação, positivos. Setorialmente, apenas se apreciam diferenças significativas em termos de produtos no setor de refino de petróleo e em termos de processo no setor de confecção. A propensão a realizar inovações radicais é maior no grupo das EMNs, como também é a propensão relativa a inovações incrementais, o que na verdade revela a maior propensão a obter resultados nas firmas geridas total ou parcialmente pelo capital estrangeiro. Este efeito é mais claro nos setores de conteúdo tecnológico médio e alto.

A propensão a patentear por vezes é maior nas empresas nacionais, em vários setores de conteúdo tecnológico baixo. No entanto, a propensão a obter receita pela comercialização de inovaçôes é maior nas EMNs na maior parte dos setores. Estes resultados revelam que: as EMNs que operam no Brasil tendem a patentear menos do que esperado, o que pode ser devido a estratégias de patenteamento globais dos resultados obtidos por elas no Brasil; as EMNs parecem ter maior facilidade para explorar seus resultados de inovação.

Apesar de não terem sido encontradas evidências de comportamento muito distinto entre EMNs e ENAs em termos agregados e para a maior parte dos setores, alguns casos excepcionais revelaram significativas diferenças de comportamento para um elevado número de variáveis examinadas. Tais diferenças foram constatadas por meio dos elevados índices de semelhança com maiores propensões nas EMNs, como nos casos dos setores de confecção, metalurgia, produtos diversos, refino de petróleo, veículos e equipamentos de comunicações. 
Outros casos de excepcionalidade compreendem pequenas diferenças de comportamento, maspara o qual, e contra o esperado, as ENAs mostravam maiores propensōes que as EMNs, concretamente no foco das suas trajetórias tecnológicas, na importância outorgada às formas de aprendizado e na obtenção de resultados. Estes são os casos dos setores de produtos diversos, instrumentos e eletrônica básica.

A explicação para estas exceções deve ser ainda pesquisada, dado que este trabalho não realiza análise sobre os determinantes das diferenças de comportamento entre ENAs e EMNs. No primeiro caso, as diferenças podem dever-se tanto à existência de ENAs dinâmicas quanto à presença de EMNs que seguem um comportamento diferenciado devido às suas características estratégicas, tal como trata a literatura. No segundo caso, parece mais clara a presença de ENAs inovadoras dinâmicas cujo foco da sua trajetória tecnológica seja diferente daquele que norteia as EMNs. Em qualquer caso, o comportamento inovador das EMNs e ENAs nestes setores não parece estar tão determinado pelos imperativos tecnológicos setoriais. Outros determinantes da atividade inovadora da firma relativos a sua estrutura organizacional, combinados com a natureza do capital, adquirem maior importância como, por exemplo, o tamanho, o poder de mercado, a acumulação de competências ou o posicionamento das firmas (ENAs e EMNs) nos mercados em que operam.

\section{Referências bibliográficas}

ARCHIBUGI, D. The sectoral structure of innovative activities in Italy. Results and methodology. Tesis (doctoral) - Universidad de Sussex, Science Policy Research Unit, Brighton, 1991. ARCHIBUGI, D.; CESARATTO, S.; SIRILLI, G. Sources of innovative activities and industrial organization in Italy. Research Policy, v. 20, p. 299-313, 1991.

CANTWELL, J. The globalism of technology: what remains of the product cycle model. Cambridge Journal of Economics, v. 19, p. 155-174, 1995.

CANTWELL, J.; JANNE, O. Technological globalisation and innovative centres: the role of corportate technological leadership and locational hierarchy. Research Policy, v. 28, p. 119-144, 1999.

COHEN, W.M.; LEVINTHAL, D.A. Innovation and learning: the two faces of R\&D. The Economic Journal, v. 99, p. 569-596, Sept. 1989.

DOSI, G. Sources, procedures and microeconomics effects of innovation. Journal of Economic Literature, v. 26, p. 1120-1171, 1988. 
Ana Urraca Ruiz, Renata Bhawan

DUNNING, J.H. Multinational enterprises and the globalisation of innovatory capacity. Research Policy, v. 23, p. 67-88, 1994.

GARCÍA-GARCÍA, C.E. El proceso de innovación en la empresa. Competencias y aprendizaje organizativos en la producción de conocimiento para la innovación. Economía Industrial, v. 301, p. 27-36, 1995.

GERYBADZE, A.; REGER, G. Globalization of R\&D: recent changes in the management of innovation in transnational corporations. Research Policy, v. 28, n. 2-3, p. 251-274, 1999.

HOWELLS, J. The location and organization of research and development: new horizons. Research Policy, v. 19, n. 2, p. 133-146, Apr. 1990.

ITO, B.; WAKASUGI, R. What factors determine the mode of overseas R\&D by multinationals? Empirical evidence. Research Policy, v. 36, n. 5, p. 1275-1287, 2007.

KLEVORICK, A.K. et al. On the sources and significance of interindustry differences in technological opportunities. Research Policy, v. 24, p. 185-205, 1995.

KUROKAWA, S. The relationship between internal R\&D capabilities and external technology adquisitions: small technology-based firms in the U.S. and Japan. In: KOJIMA, $\mathrm{K}$. (Ed.). Innovation and business dynamism in Japan and Korea. Kobe, Kobe University, 1992. p. 101-111.

LEVIN, R.C. Appropriability, R\&D Spending, and Technological Performance. American Economic Review, v. 78, n. 2, p. 424-428, May 1988.

LEVIN, R.C. et al. Appropriating the returns from industrial research and development. Brookings Papers on Economic Activity, v. 3, p. 783-820, 1987.

MALERBA, F. Learning by firms and incremental technical change. The Economic Journal, n. 102 , p. 845-859, 1992.

MALERBA, F.; ORSENIGO, L. Technological regimes and patterns of innovation: a theoretical and empirical investigation of the italian case. In: HEERTJE A.; PERLMAN M., (Ed.). Evolving Technology and Market Structure: Studies in Schumpeterian Economics. USA: The University of Michigan Press, 1990. p. 283-305.

MANSFIELD., E.; RAPOPORTS, J. The costs of industrial products innovations. Management Science, v. 21, n. 12, p. 1380-1386, Ago. 1975.

OCDE. Proposed Guidelines for collecting and interpreting technological innovation data: Oslo manual. 1. ed. Paris: OCDE, 1992.

PATEL, P.; PAVITT, K. Patterns of technological activity: their measurement and interpretation. In: STONEMAN P. (Ed.). Handbook of the economics of innovation and technological change. Oxford: Blackwell Publishers LTD, 1995. 
PATEL, P.; VEGA, M. Patterns of internationalisation of corporate technology: location versus home country advantages. Research Policy, v. 28, n. 2-3, p. 145-155, 1999.

PAVITT, K. Sectoral patterns of technical change: towards a taxonomy and a theory. Research Policy, v. 13, n. 6, p. 343-373, 1984.

PEARCE, R.D. Factors influencing the internationalization of R\&D in multinational enterprises. In: BUCKLEY, P.J.; CASSON, M. Multinational enterprises in the world economy. England: Edgar Elgar Publishing LTD, 1992.p. 75-95.

VON HIPPEL, E. The sources of innovation. Oxford: Oxford University Press. 1988. 
Ana Urraca Ruiz, Renata Bhawan

ANEXO 1

Definição de variáveis

\begin{tabular}{|c|c|c|c|}
\hline Variável & Descrição & Toma valor $1 \mathrm{SE}$ & Toma valor $0 \mathrm{SE}$ \\
\hline ENAC & Empresas com capital estritamente nacional & $\mathrm{P} 1=1$ & P1 = qualquer outro valor \\
\hline EMN & Empresa com participação de capital estrangeiro & $\begin{array}{l}P 1=2 \text { ou } \\
P 1=3\end{array}$ & P1 = qualquer outro valor \\
\hline EIN & Empressa inovadora & $\begin{array}{l}E D R=1 \text { ou } \\
E O R=1 \text { ou } \\
E I S=1\end{array}$ & Qualquer outro caso \\
\hline EDR & Empresa que destina recursos a inovação & 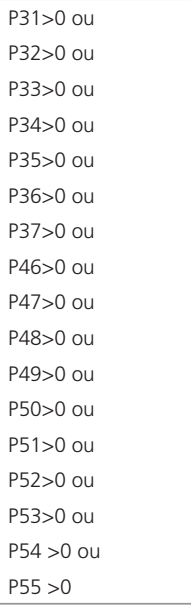 & Qualquer outro caso \\
\hline EOR & Empresa que obtém resultados de inovação & 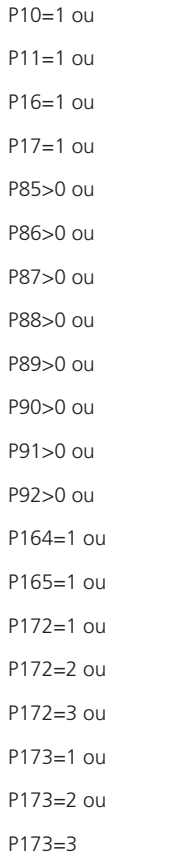 & Qualquer outro caso \\
\hline
\end{tabular}


ANEXO 1

Definição de variáveis

\begin{tabular}{|c|c|c|c|}
\hline Variável & Descrição & Toma valor $1 \mathrm{SE}$ & Toma valor $0 \mathrm{SE}$ \\
\hline EIS & Empresa que realiza inovação de sistemas & $\begin{array}{l}\text { P188=1 ou } \\
\text { P189=1 ou } \\
\text { P190=1 ou } \\
\text { P191=1 ou } \\
\text { P192=1 ou } \\
\text { P193=1 ou } \\
\text { P194=1 ou } \\
\text { P195=1 ou } \\
\text { P196=1 }\end{array}$ & Qualquer outro caso \\
\hline EAIN & Empresa altamente inovadora & $\begin{array}{l}E R I=1 \mathrm{e} \\
P 11=1 \mathrm{e} \\
\mathrm{P} 17=1\end{array}$ & Qualquer outro caso \\
\hline ERI & Empresa dedica algum recurso interno & $\begin{array}{l}\mathrm{P} 108=\text { Alta ou } \\
\mathrm{P} 109=\text { Alta e } \\
\mathrm{EPD}=1\end{array}$ & Qualquer outro caso \\
\hline EPD & Empresa que realiza $P \& D$ & $\begin{array}{l}\mathrm{P} 31>0 \text { ou } \\
\text { P46 }>0 \text { ou } \\
\text { P47 }>0 \text { ou } \\
\text { P48 }>0 \text { ou } \\
\text { P49 }>0 \text { ou } \\
\text { P50 }>0 \text { ou } \\
\text { P51 }>0 \text { ou } \\
\text { P52 }>0 \text { ou } \\
\text { P53 }>0 \text { ou } \\
\text { P54 }>0 \text { ou } \\
\text { P55 }>0\end{array}$ & Qualquer outro caso \\
\hline EINI & $\begin{array}{l}\text { Empresa que gasta em fontes internas } \\
\text { exclusivamente }\end{array}$ & $\begin{array}{l}E P D=1 \mathrm{e} \\
E I N E=0\end{array}$ & Qualquer outro caso \\
\hline EINE & $\begin{array}{l}\text { Empresa que gasta em fontes externas } \\
\text { exclusivamente }\end{array}$ & $\begin{array}{l}E P D=0 \text { e } \\
P 32>0 \text { ou } \\
\text { P33>0 ou } \\
\text { P34>0 ou }\end{array}$ & Qualquer outro caso \\
\hline EMIX & Empresa que gasta algum recurso interno e externo & $\begin{array}{l}E P D=1 \text { e } \\
E R E=1\end{array}$ & Qualquer outro caso \\
\hline EPDE & Empresa que gasta em P\&D externo & P32>0 & Qualquer outro caso \\
\hline ETEX & Empresa que gasta em outros conhecimento externos & P33 $>0$ & Qualquer outro caso \\
\hline EQUIP & Empresa que gasta em máquinas e equipamentos & P34>0 & Qualquer outro caso \\
\hline FINT & Empresas que usa fontes internas de conhecimento & $\begin{array}{l}\text { P108 = Alta ou } \\
\text { P109 = Alta }\end{array}$ & Qualquer outro caso \\
\hline
\end{tabular}


Ana Urraca Ruiz, Renata Bhawan

ANEXO 1

Definição de variáveis

\begin{tabular}{|c|c|c|c|}
\hline Variável & Descrição & Toma valor $1 \mathrm{SE}$ & Toma valor $0 \mathrm{SE}$ \\
\hline LEARN & Aprendizado pelo treinamento & $\begin{array}{l}\text { P28 }=\text { Alta e } \\
\text { P35 }>0\end{array}$ & Qualquer outro caso \\
\hline INTERACT & Aprendizado pela interação & $\begin{array}{l}\mathrm{P} 111=\text { Alta ou } \\
\mathrm{P} 112=\text { Alta ou } \\
\mathrm{P} 113=\text { Alta ou } \\
\mathrm{P} 118=\text { Alta ou } \\
\mathrm{P} 119=\text { Alta ou } \\
\mathrm{P} 120=\text { Alta ou } \\
\mathrm{P} 134=1\end{array}$ & Qualquer outro caso \\
\hline HIRING & Aprendizado pela subcontratação & $\begin{array}{l}\mathrm{P} 114=\text { Alta ou } \\
\text { P115 }=\text { Alta ou } \\
\text { P116 }=\text { Alta ou } \\
\text { P117 = Alta }\end{array}$ & Qualquer outro caso \\
\hline EIPROD & Empresa que realiza inovação de produtos & $\begin{array}{l}P 10=1 \text { ou } \\
P 11=1\end{array}$ & Qualquer outro caso \\
\hline EIPROC & Empresa que realiza inovação de proceso & $\begin{array}{l}P 16=1 \text { ou } \\
P 17=1\end{array}$ & Qualquer outro caso \\
\hline RADIC & Empresa que realiza inovações radicais & $\begin{array}{l}\mathrm{P} 11=1 \text { ou } \\
\mathrm{P} 13=3 \text { ou } \\
\mathrm{P} 13=4 \text { ou } \\
\mathrm{P} 17=1 \text { ou } \\
\mathrm{P} 19=3 \text { ou } \\
\mathrm{P} 19=4 \text { ou } \\
\mathrm{P} 86>0 \text { ou } \\
\text { P87 }>0 \text { ou } \\
\text { P90 }>0 \text { ou } \\
\text { P91 }>0 \text { ou } \\
\text { P172=2 ou } \\
\mathrm{P} 172=3 \text { ou } \\
\mathrm{P} 173=2 \text { ou } \\
\text { P173=3 }\end{array}$ & Qualquer outro caso \\
\hline INCR & Empresa que realiza inovação incremental & $\begin{array}{l}P 10=1 \text { ou } \\
P 16=1 \text { ou } \\
P 85>0 \text { ou } \\
P 89>0 \text { ou } \\
P 172=1 \text { ou } \\
P 173=1\end{array}$ & Qualquer outro caso \\
\hline
\end{tabular}


ANEXO 2

Médias das distâncias, por grupos de setores de acordo com conteúdo tecnológico

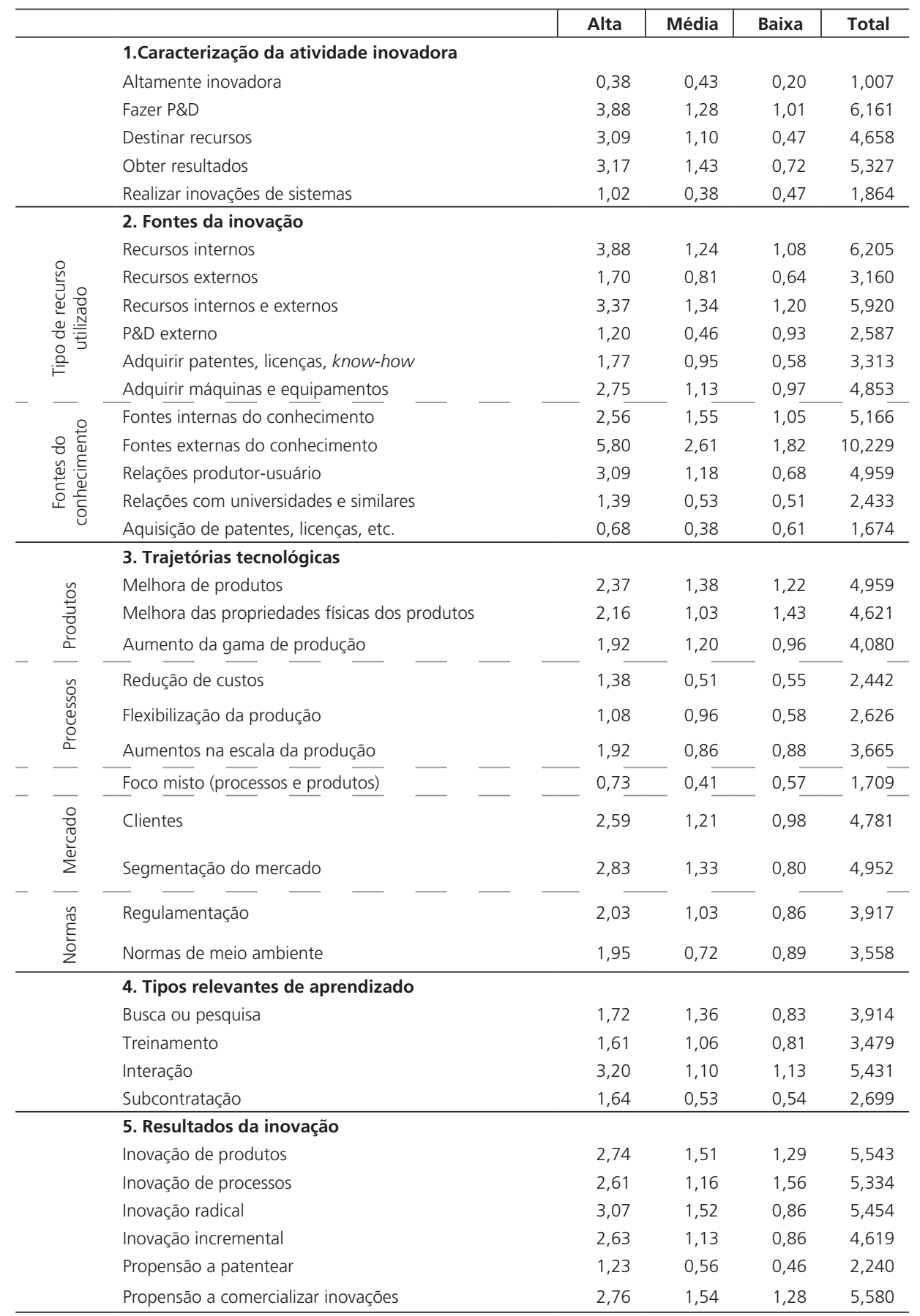

Fonte: Elaboração própia. 
Ana Urraca Ruiz, Renata Bhawan

ENDEREC OS PARA CORRESPONDENCIA:

Ana Urraca Ruiz - anaruiz@economia.uff.br

Rua Tiradentes, 17. Ingá. Niterói. RJ

Renata Bhawan de Amorim - renatabhawan@petrobras.com.br Av. República do Chile, 65 - 2202 A - Centro

20031-912 - Rio de Janeiro - RJ - Brasil

Tel: (21) 3224-2073 